NBER WORKING PAPER SERIES

INTEREST RATES, MONEY SUPPLY ANNOUNCEMENTS, AND MONETARY

BASE ANNOUNCEMENTS

John Huizinga

Leonardo Leiderman

Working Paper No. 1705

NATIONAL RUREAU OF ECONOMIC RESEARCH 1050 Massachusetts Avenue

Cambridge, MA 02138

September 1985

We thank Ken French, Richard Leftwich and seminar participants at the University of Chicago, Stanford University, and University of California, Berkeley for helpful comments. The research reported here is part of the NBER's research programs in Economic Fluctuations and Financial Markets and Monetary Economics. Any opinions expressed are those of the authors and not those of the National Bureau of Economic Research. 
NBER Working Paper \#1705

September 1985

\section{Interest Rates, Money Supply \\ Announcements, and Monetary \\ Base Announcements}

\section{ABSTRACT}

This paper presents a new set of empirical regularities on the link between interest rates, money supply announcements and monetary base announcements. Among the main findings reported are: (i) unexpected increases in the announced monetary base have a significantly positive effect on interest rates during the period from October 1979 to October 1982; (ii) although unexpected money supply and monetary base announcements have the same impact on interest rates, they have different implications for the future behavior of the money supply and monetary base; (iii) the significant response of longer-term interest rates to unexpected monetary announcements is reflecting a response of current and expected future shortterm rates -- i.e. term-structure premia are not altered by these announcements.

John Huizinga

Graduate School of Business

University of Chicago

1101 E. 58th Street

Chicago, IL 60637

(312) $962-7272$
Leonardo Leiderman

Department of Economics

Tel-Aviv University

Ramat Aviv 69978

Tel-Aviv, ISRAEL

011-972-52-449117 


\section{Introduction}

Recent empirical research on the effects of weekly money supply announcements has produced a number of interesting findings. ${ }^{1}$ Unexpected increases in the announced money supply have a positive and statistically significant impact on the interest rates of both short-term and long-term assets. The magnitude and significance of these impacts show a marked increase following the October 6, 1979 change in the Federal Reserve's operating procedures. Expected increases in the announced money supply generally have a negative effect on interest rates, but the statistical significance of the effect depends on the time period being examined and on the method of measuring expectations.

Although these findings are informative, a number of important questions remain unanswered. For example, are money supply announcements affecting interest rates because of the information they convey about the monetary base or about the money multiplier? Are there effects of the weekly monetary base announcements on interest rates? Do interest rates respond to the weekly announcements of money supply and monetary base revisions? What are the predictive implications of monetary announcements for the expected future behavior of the money supply and monetary base? Is the interest ratemonetary announcement link altered at the time of the October 1982 shift in Federal Reserve operating procedure? Are the effects of monetary announcements on long-term interest rates capturing their effects on expected future short-term interest ratęs or on term-structure premia?

The main purpose of this paper is to provide answers to these questions. In addition, the robustness of previously reported findings is examined. Thus, the contribution is to present a new, expanded set of 
empirical regularities which characterize the monetary announcement-interest rate link. The key results reported in the paper are:

(i) There is a significant positive link between monetary base announcements and interest rates, a relation which previous researchers have either ignored or failed to detect: Allowing for this link does not alter the strength of the relation between money supply announcements and interest rates. The hypothesis that unexpected monetary base and money supply announcements have the same impact on interest rates cannot be statistically rejected at standard significance levels. Given the delays in announcing monetary data, a money supply announcement provides new information about only the money multiplier. Thus, interest rates significantly respond to new information about both the monetary base and the money multiplier.

(ii) Significant interest rate responses to monetary announcements exist only for announcements of preliminary data. Announcements of money supply and monetary base revisions do not have a significant impact on interest rates.

(iii) During the time period when announcements have their largest impact on interest rates, both unexpected money supply and monetary base announcements contain useful information for predicting future monetary developments. An unexpected increase in the announced money supply can be used to predict subsequent money supply contractions. These contractions only partially offset the initial expansion, however, so that higher levels of the money supply can be expected to prevail in periods after such an announcement. Despite this information about subsequent money supplies, unexpected money supply announcements generally have no predictive power for future levels of the monetary base. An unexpected increase in the announced monetary base signals different monetary developments than an unexpected 
increase in the announced money supply. It can be used to predict lower money supplies in the future as well as subsequent changes in the monetary base. An unexpected increase in the announced monetary base is followed by a significant contraction of the base which only partially offsets the initial change. The finding that unexpected money supply and monetary base announcements have different predictive implications but have similar effects on interest rates casts doubt on the proposition that the observed monetary announcement-interest rate link can be fully accounted for in terms of the new information they convey about future money supply and monetary base behavior.

(iv) Following the October 1982 shift in the Federal Reserve's operating procedure there was a statistically significant change in the monetary announcement-interest rate relation. The impact of monetary announcements on interest rates is much smaller after the Federal Reserve began to downplay its committment to hitting a target growth rate of the Ml money supply. There are also changes in the ability of unexpected announcements to predict future monetary developments.

(v) The rise in long-term interest rates following an unexpected increase in the announced money supply and monetary base appears to result only from the movement of current and expected future short-term interest rates. That is, there is no evidence of a significant response of termstructure premia to unexpected monetary announcements.

(vi) Some previous empirical work on the link between monetary announcements and interest rates in the pre-October 1979 period may be misleading for two reasons. First, changes in interest rate volatility from 1977 to 1979 have the consequence that interest rate regressions estimated over this period exhibit significant heteroskedasticity. Failure to take 
account of this can result in improper statistical inference. Second, and more importantly, an examination of the role of influential data points shows that before 1979 the statistically significant link between monetary announcements and interest rate changes is attributable to a relatively few data points.

The paper is organized as follows. Section II describes the data and introduces notation. Section III presents results concerning the impact of expected and unexpected money supply announcements on the interest rate for three-month U.S. Treasury bills. Three sample periods are examined: preOctober 1979, October 1979-October 1982, and post-October 1982. Section IV assesses the stability of these results, both within and across samples, as well as the role of potentially influential observations. The interest rate effects of monetary base announcements are analyzed in section $V$. This section also examines whether interest rates respond to announced revisions of previously reported money supply and monetary base data. Section VI evaluates the predictive ability of unexpected monetary announcements for the subsequent behavior of the money supply and the monetary base. The effects of monetary announcements on longer-term interest rates are investigated in section VII. This section also provides evidence on whether the reaction of longer-term interest rates to the annnouncements reflects a change in expected future short-term rates and/or a change in term-structure premia. Section VIII contains concluding remarks. 
II. Notation and Data Description

Four sources of data are used in this paper. The weekly H.6 release of the Board of Governors of the Federal Reserve System is used for money supply data. During the time period examined here, September 29, 1977 to March 29, 1984, this release contains a preliminary announcement of the average money supply over the week ending approximately nine days ago and the announcement of a revised estimate of the average money supply over the week ending approximately sixteen days ago. These variables are subscripted by the week in which they become known. The preliminary money supply announcement which is released in week $t$ is denoted $M_{t}$ and the revised estimate which is released at this time is denoted $M L R_{t}$.

Up until January 31,1980 , the H.6 release was scheduled to be made public every Thursday at 4:10 p.m. The regularly scheduled time was changed to Friday at 4:10 p.m. beginning with the February 8, 1980 announcement. Friday announcements remained the rule until February 10, 1984. Beginning with the February 16, 1984 announcement the scheduled release time was returned to Thursday at 4:10 p.m. Despite this schedule, actual announcements are not always made at the regularly scheduled time due to factors such as holidays and delays in gathering data. This fact has been taken into account in the construction of the data set.

The definition of money used in this paper is Ml from the beginning of the sample until January 31, 1980 and from January 15, 1982 until the end of the sample, but is M1-B from February 8, 1980 until January 8, 1982. These dates for switching the definition of money correspond to the dates at which the definitions change in the published data. Until February 10, 1984 the weekly money supply data are daily averages from Thursday to Wednesday, 
while beginning February 16, 1984 they are daily averages from Tuesday to Monday.

The weekly H.9 press release of the Board of Governors of the Federal Reserve System contains monetary base data. This release is available only from March 15, 1979 until February 10, 1984. Although, the regularly scheduled time for the H.9 release is the same as for the H.6 release, there are weeks when the two releases are not made on the same day. When examining the interest rate effects of both money supply and monetary base announcements, data for these weeks are not used in the analysis.

The timing of the data in the H.9 release differs from the timing of the data in the H.6 release; the preliminary announcement is for the average monetary base during the week ending approximately two days ago and the revised estimate is for the average monetary base during the week ending approximately nine days ago. The preliminary monetary base announcement which is released in week $t$ is denoted $B_{t}$ and the revised estimate which is released in week $t$ is denoted $B L R_{t}$. The monetary base announcements are always for a week ending Wednesday.

The fact that monetary base announcements are made with a two day delay and that money supply announcments are made with a nine day delay is important for understanding what information is being revealed by a money supply announcement. When an announcement is made in week $t$ about the money supply in week $t-1$, the monetary base for week $t-1$ has already been announced. Thus, the money supply announcement provides new information about only the money multiplier.

The monthly G.13 press release of the Board of Governors of the Federal Reserve System provides interest rate data. The release contains daily interest rates for U.S. Treasury bills of three-, six-, and twelve-month 
maturity. The rates are from dealer quotations in the secondary market, at approximately 3:30 p.m.. Given this timing, the interest rates available for the day of a money supply or monetary base announcement are rates before the announcement. For week $t, R 3 B_{t}$ and $R 3 A_{t}$ are the annualized interest rates on three-month U.S. Treasury bills on the day of a money supply announcement and on the first trading day after a money supply announcement, respectively. A similar definition applies to $R 6 B_{t}, R 6 A_{t}, R I 2 B_{t}$ and $R 12 A_{t}$ interest rates for six- and twelve-month U.S. Treasury bills.

Money Market Services, a Belmont, California based corporation which has conducted telephone surveys of approximately fifty government securities dealers since late 1977, has kindly provided their weekly measure of money supply announcement forecasts. Money Market Services conducts their surveys every Tuesday, asking for an estimate of the money supply change that will be announced later in the week. The data were made available beginning with the announcement made on September 29, 1977 and ending with the announcement made on March 29, 1984. The series used here, XMES ${ }_{t}$, is the median forecast of all those surveyed.

III. The Money Supply Announcement-Interest Rate Relation

This section presents results which extend the widely documented relation between money supply announcements and interest rates through March 1984. In particular, the first three regressions presented in Table I relate the change in the interest rate on three-month U.S. Treasury bills 
$\left(D R 3_{t}-R 3 A_{t}-R 3 B_{t}\right)$ to the unexpected and expected components of money supply announcements. The weekly announcement of a change in the money supply has been decomposed into expected and unexpected components (XMES ${ }_{t}$ and $\mathrm{XMUS}_{t}-\mathrm{M}_{t}-\mathrm{MLR} \mathrm{R}_{t}-\mathrm{XMES}_{t}$ ) using the Money Market Services survey measure of expectations. 2 The data have been divided into three samples with A.I covering September 29, 1977 to October 4, 1979, B.1 covering October 11, 1979 to October 15, 1982, and C.1 covering October 22, 1982 to March 29, $1984 .^{3}$

The regression results show a positive and statistically significant link between unexpected money supply announcements and interest rates in all three periods examined. ${ }^{4}$ Further, the magnitude of the interest rate change in response to news about the money supply varies considerably across samples. In the pre-October 1979 period an unexpected increase of one billion dollars in the announcad money supply raises the annualized interest rate on three-month U.S. Treasury bills by less than two basis points. From October 1979 to October 1982 the impact is over four times as large, nearly nine basis points. From October 1982 to March 1984 the impact drops back to just over three basis points. The substantial rise in the magnitude of the impact that unexpected money supply announcements have on interest rates after October 1979 is mostly reversed after October $1982 .^{5}$

Higher expected money announcements are associated with decreases in interest rates in all samples. While expected money supply announcements do not have significant explanatory power for interest rate changes pre-October 1979 or post-October 1982, they do have significant explanatory power from October 1979 to October 1982. ${ }^{6}$ The existence of a predictable change in the interest rate has often been interpreted as evidence against an efficient bond market. However, this interpretation need not be correct. No violation of bond market efficiency can be determined without explicitly considering 
the nature of the risk involved with basing portfolio decisions on expected interest rate changes.

Also of interest in the results of Table 1 are the standard errors of the regressions, which are consistent with the well-known high level of interest rate volatility for the period October 1979 to October 1982. During this period, the standard deviation of the daily change in the interest rate that cannot be explained by money supply announcements is over three times larger than it is in the preceding and subsequent periods. Despite the high standard error of the regression in the October 1979 to October 1982 period, however, the adjusted $\mathrm{R}^{2}$ is approximately the same during the entire postOctober 1979 sample. Money supply announcements explain between 258 and 30\% of the one day movement in interest rates during this time.

IV. Stability and the Importance of Influential Observations

The differences in the magnitude of the impact that money supply announcements have on interest rates in different time periods appear sufficiently large to justify the contention that the relation has not been constant over time. Such differences may also lead one to question the stability of the money supply announcement-interest rate link within each of the sample periods in Table 1 . This section demonstrates that the relation is apparently stable within the October 1979 to October 1982 and postOctober 1982 samples but not within the pre-October 1979 sample. The instability is linked to the role of a relatively few influential observations and to significant heteroskedasticity. After accounting for the instability in the pre-1979 sample, it is shown that the money supply 
announcement-interest rate relation is significantly different across the pre-October 1979, October 1979 to October 1982 and post-October 1982 samples.

The issue of within sample stability is addressed by the test statistics found in the last two columns of Table 1. The number in parentheses below a test statistics is its marginal significance level, so that a value less than .05 indicates rejection of the null hypothesis at the 58 level. The last column provides the standard Chow test statistic for testing coefficient stability within the sample. ${ }^{7}$ The column entitled G-Q TEST is a Goldfeld-Quandt test for heteroskedasticity, where the observations are ordered chronologically. ${ }^{8}$ This test was used to uncover any time trend behavior in the variance of the regression error.

For the October 1979 to October 1982 and post-October 1982 samples, neither the hypothesis of coefficent stability nor the hypothesis of constant error variance can be rejected using standard significance levels. In the pre-October 1979 sample, however, it is possible to reject both hypotheses at the $5 \%$ significance level.

Some insight into the nature of the instability of the money supply announcement-interest rate relation in the pre-October 1979 period can be obtained by examining the scatter plots displayed in Figures 1 and 2 . Due to the near orthogonality of XMUS and XMES, it is useful to examine bivariate scatter plots of DR3 vs. XMUS (Figure 1) and DR3 vs. XMES (Figure 2). 9 The primary points of interest in Figure 1 are the observations for April 26, 1979 (denoted as point a) and for November 9, 1978 (denoted as point b). These points appear to be influential in the sense that dropping them from the sample would noticeably reduce the estimated coefficient on XMUS. Since both of these points fall in 
FIGURE 1

PLOT OF DR3 vS XMUS, PRE-OCTOBER 1979

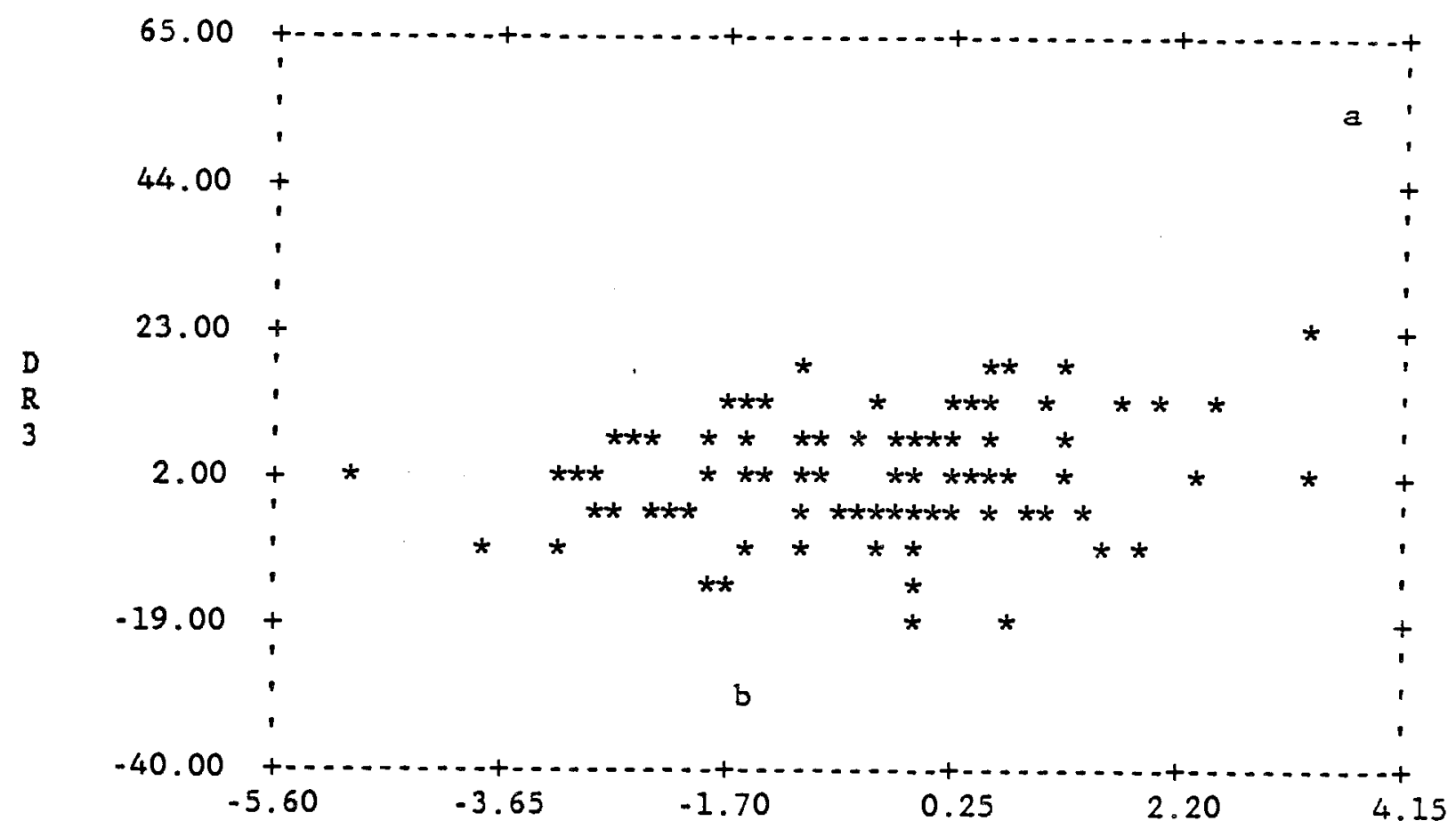

XMUS

Note: DR3 is the change in the annualized interest rate on three-month U.S. Treasury bills from the close of the market on the day of a money supply announcement to the close of the market on the following day, measured in basis points. XMUS is the unexpected change in the money supply announcement, based on the Money Market Services survey and measured in billions of dollars. ' $a$ ' represents the observation for April 26, 1979 and 'b' represents the observation for November 9, 1978. A '*' represents other, possibly multiple, observations. There are a total of 106 observations; representing weekly data from

September 29, 1977 to October 4, 1979. 
FIGURE 2

PLOT OF DR3 VS XMES, PRE-OCTOBER 1979

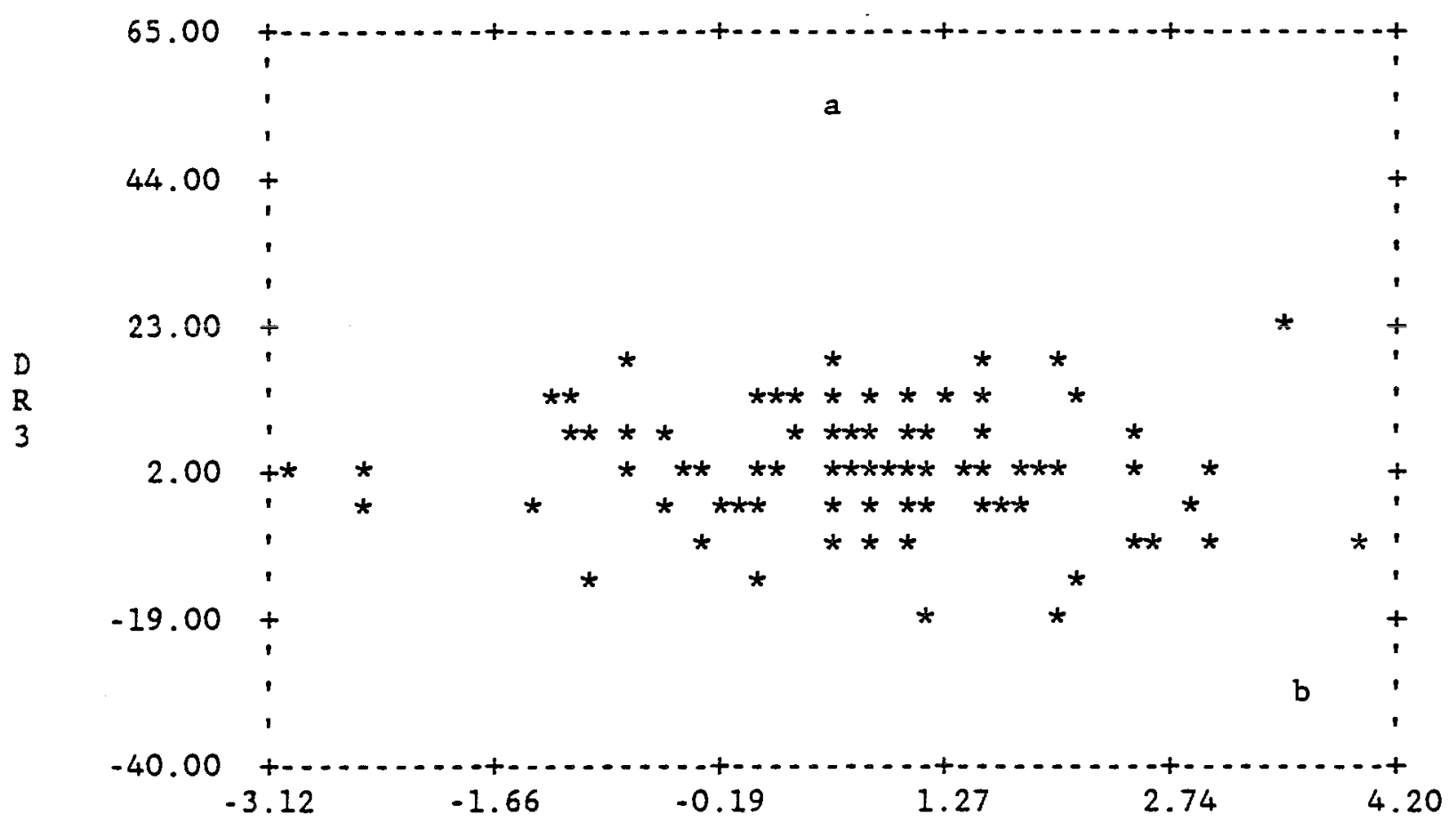

Note: DR3 is the change in the anuualized interest rate on three-month U.S. Treasury bills from the close of the market on the day of a money supply announcement to the close of the market on the following day, measured in basis points. XMES is the expected change in the money supply announcement, based on the Money Market Services survey and measured in billions of dollars. ' $a$ ' represents the observation for April 26, 1979 and 'b' represents the observation for November 9, 1978. A '*' represents other, possibly multiple, observations. There are a total of 106 observations, representing weekly data from September 29, 1977 to October 4, 1979. 
the second half of the sample, it is not surprising that the Chow test indicates coefficient instability. ${ }^{10}$ Figure 2 shows the observations for April 26, 1979 and November 9, 1978 in the bivariate scatter plot of DR3 vs. XMES.

The effect of dropping the influential points mentioned above is shown in the results for sample A.2 in Table 1 . The significant impact that unexpected money supply announcements have on interest rate changes is lost when the two influential points are omitted from the sample. The estimated impact drops by over 50\%, from 1.77 basis points to 0.80 . Also of interest in the results for sample A.2 is the fact that while dropping the influential points is apparently sufficient to stabilize the estimated coefficients, it is not sufficient to eliminate the heteroskedasticity of the error term. A closer examination of the data indicated that the heteroskedasticity was caused by an error variance which grows over the sample. Dropping the observations before March 30, 1978, in addition to the influential points, is sufficient to construct a pre-October 1979 sample which has both constant coefficients and constant error variance. ${ }^{11}$ The effect of dropping these observations is shown in the results for sample A. 3 in Table 1. In this sample neither unexpected nor expected money supply announcements have a significant impact on interest rate changes.

Determining whether there was a significant link between money supply announcements and interest rates during the pre-October 1979 period is difficult in light of the results for samples A.2 and A.3. That is, the observations for April 26, 1979 and November 9, 1978 are clearly influential, but they cannot be considered "outliers" or "bad" observations without additional information. Interestingly, Grossman (1981) and Roley $(1982,1983)$ report estimates of the impact of unexpected money supply 
announcement on interest rates which are close to those reported in Table 1 for sample A.2, i.e. for the sample which drops influential observations. ${ }^{12}$ Since these authors measure interest rate changes over a one and a half hour interval on the day of the announcement instead of the twenty four hour interval considered here, the influential points appear to be a reflection of interest rate movements which are occurring during the day following the announcement. Presumably, this is a reaction to events other than the money supply announcement and it seems appropriate to delete the influential observations when measuring the impact of money supply announcements.

Figures 3 through 6 contain the same type of information as Figures 1 and 2 , but for different time periods. Figures 3 and 4 are for October 1979 through October 1982 while Figures 5 and 6 are for post-October 1982. The scatter plots are informative, even though regression diagnostics indicate no apparent instability during these latter time periods. Examination of Figures 3 through 6 shows that, in contrast to the results for pre-October 1979, during the latter periods there is no obvious, small set of points which underly the statistically significant relations reported in Table 1. The relation between unexpected money supply announcements and interest rates is seen in Figures 3 and 5 to be a result which appears characteristic of the entire sample. Figure 4 illustrates a similar finding for the link between expected money announcements and interest rates.

The final issue addressed in this section is the stability of the money supply announcement-interest rate link across the three stable periods identified in the regressions of Table 1 . The statistics presented at the bottom of the table test the null hypothesis that the coefficients $a_{1}$ and $a_{2}$ are equal in the two, or three, samples indicated. ${ }^{13}$ They indicate that the October 1979 to October 1982 period is significantly different from the 
FIGURE 3

PLOT OF DR3 VS XMUS, OCTOBER 1979 TO OCTOBER 1982

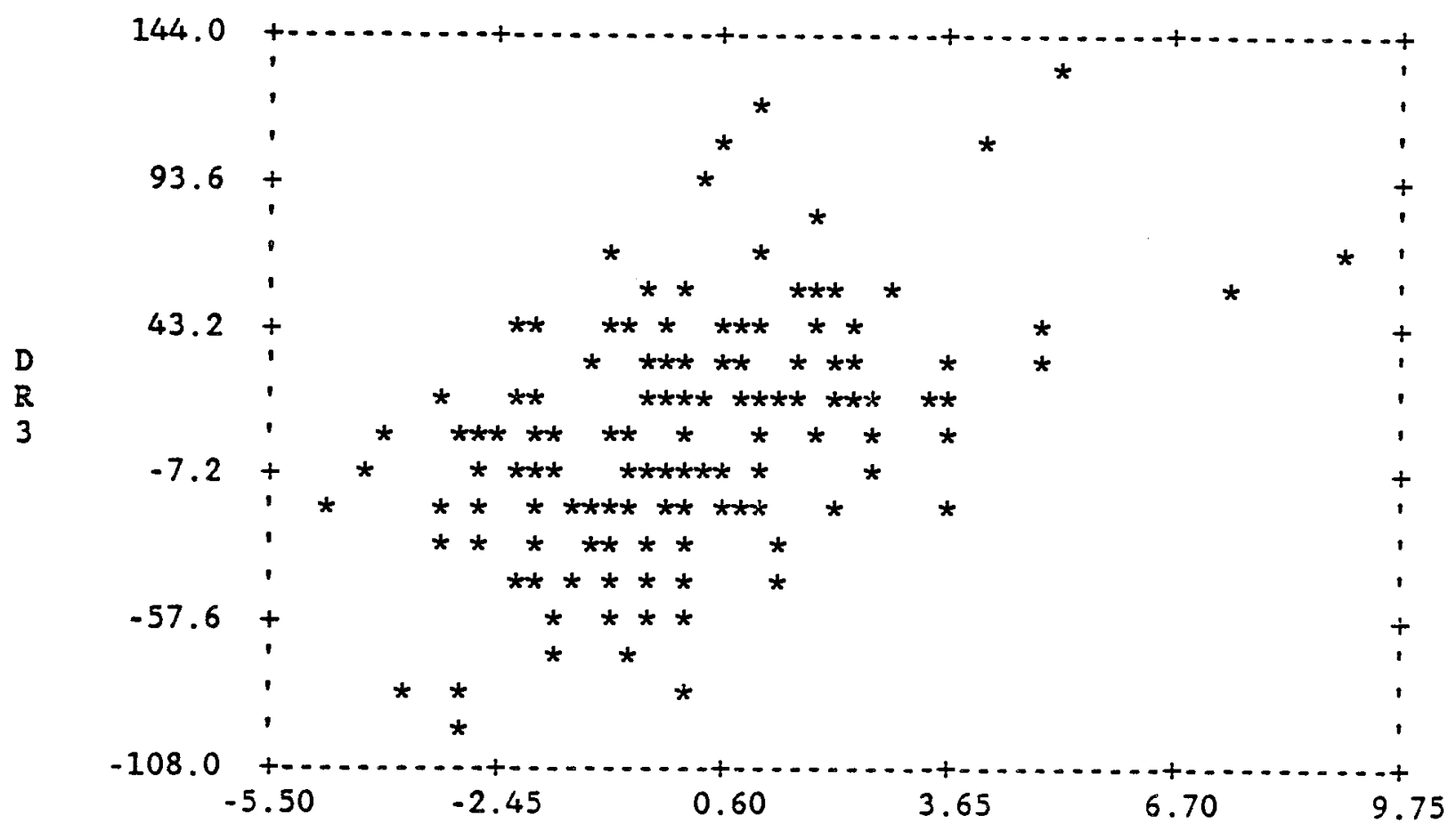

XMUS

Note: DR3 is the change in the annualized interest rate on three-month U.S. Treasury bills from the close of the market on the day of a money supply announcement to the close of the market on the following day, measured in basis points. XMUS is the unexpected change in the money supply announcement, based on the Money Market Services survey and measured in billions of dollars. A ' $*$ ' can represent either one or multiple observations. There are a total of 156 observations, representing weekly data from October 11, 1979 to October 15, 1982. The observations for February 8,1980 and January 15, 1982 have not been plotted. February 8,1980 is the date at which the published money definition changes from M1 to M1B. January 15, 1982 is the date at which the published definition changes from MlB to Ml. 
FIGURE 4

PLOT OF DR3 VS XMES, OCTOBER 1979 TO OCTOBER 1982

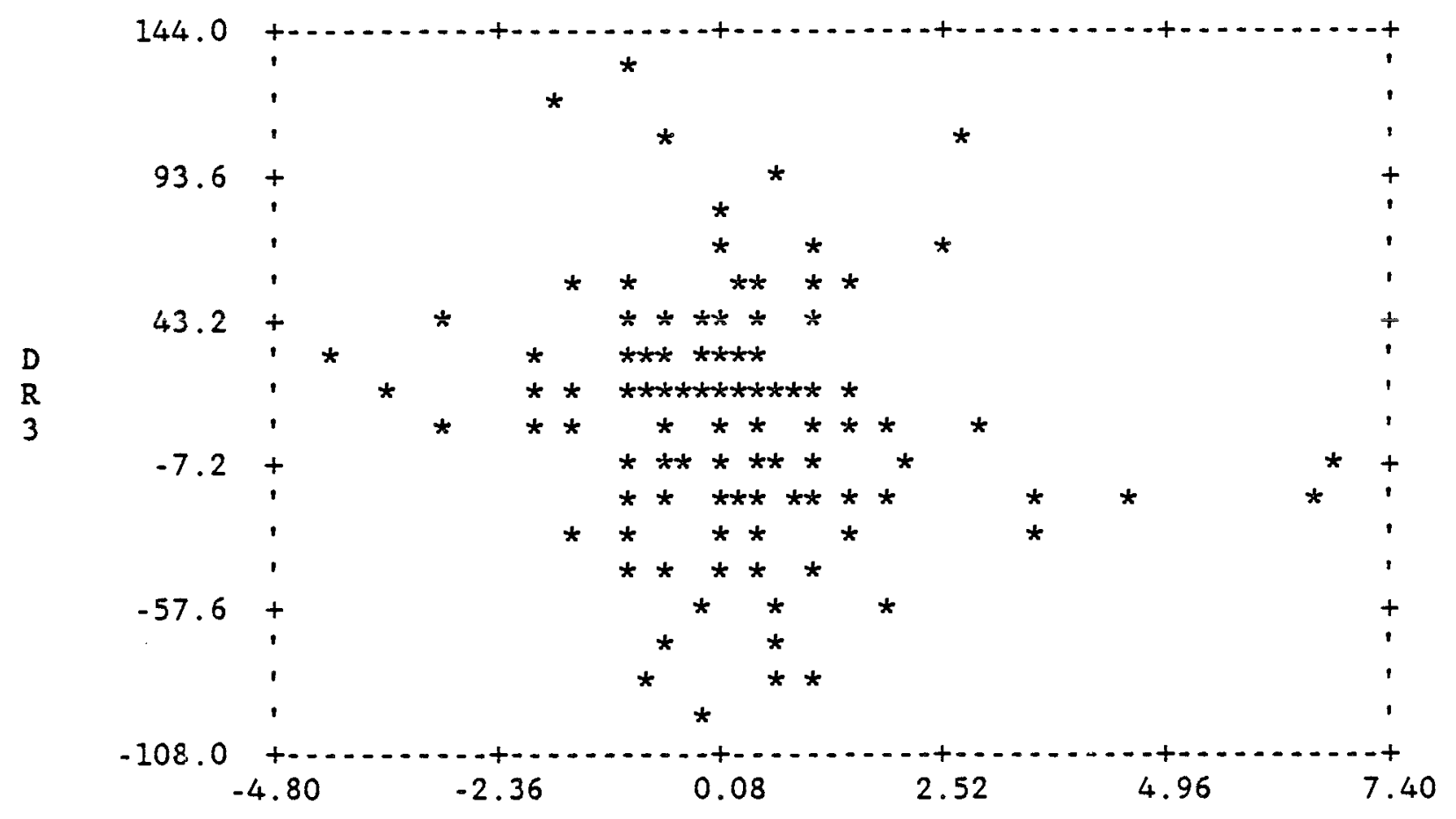

XMES

Note: DR3 is the annualized change in the interest rate on three-month U.S. Treasury bills from the close of the market on the day of a money supply announcement to the close of the market on the following day, measured in basis points. XMES is the expected change in the money supply announcement, based on the Money Market Services survey and measured in billions of dollars. A ' $*$ ' can represent either one or multiple observations. There are a total of 156 observations, representing weekly data from October 11, 1979 to October 15, 1982. The observations for February 8,1980 and January 15, 1982 have not been plotted. February 8,1980 is the date at which the published money definition changes from M1 to M1B. January 15, 1982 is the date at which the published definition changes from M1B to M1. 
FIGURE 5

PLOT OF DR3 VS XMUS, POST-OCTOBER 1982

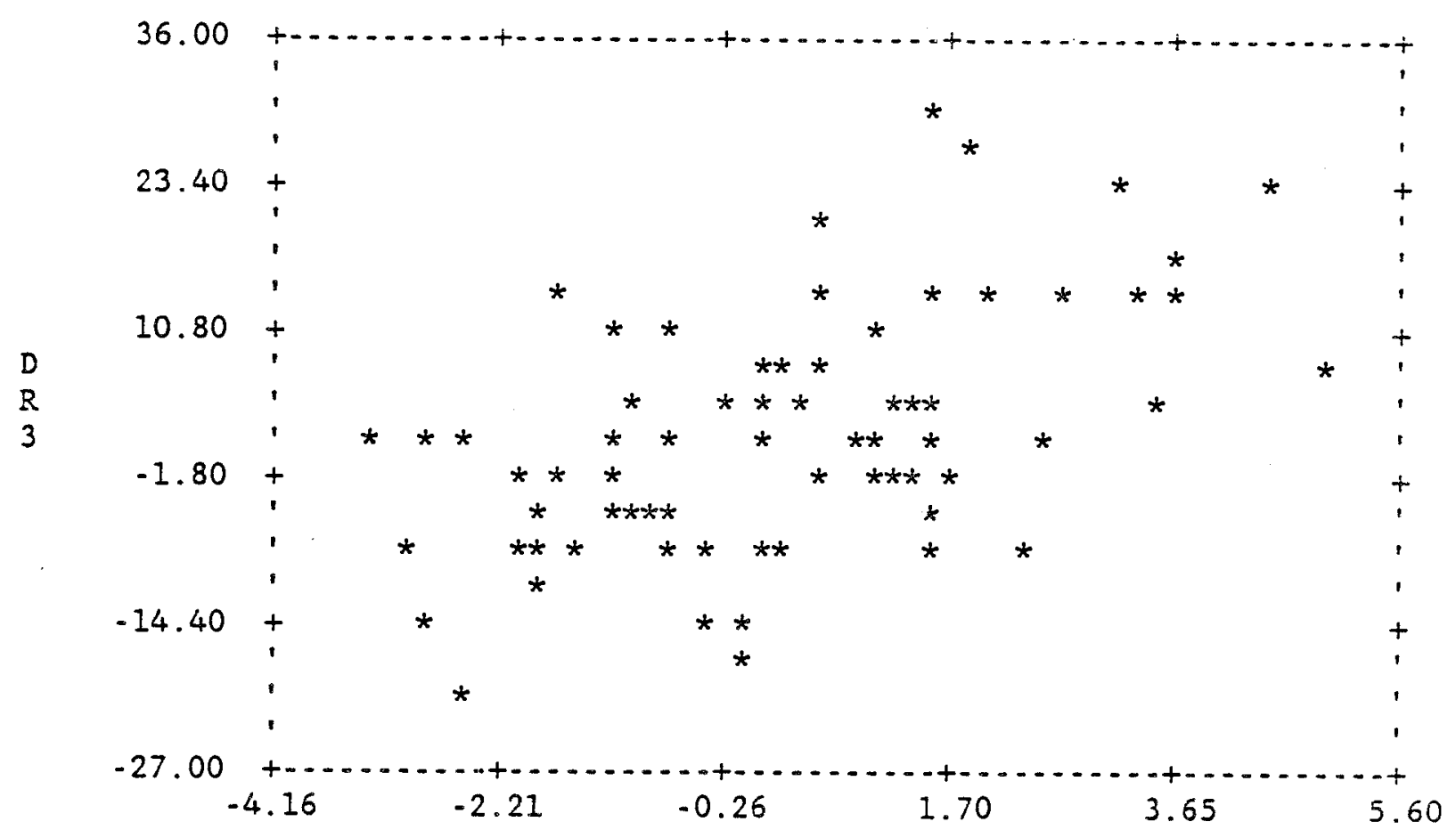

XMUS

Note: DR3 is the change in the annualized interest rate on three-month U.S. Treasury bills from the close of the market on the day of a money supply announcement to the close of the market on the following day, measured in basis points. XMUS is the unexpected change in the money supply announcement, based on the Money Market Serrices survey and measured in billions of dollars. A ' *' represents other, possibly multiple, observations. There are a total of 75 observations, representing weekly data from October 22, 1982 to March 29, 1984. The observation for February 14, 1983 has not been plotted since there appears to be a typographical error in the money supply revision announced on that date. 
FIGURE 6

PLOT OF DR3 VS XMES, POST-OCTOBER 1982

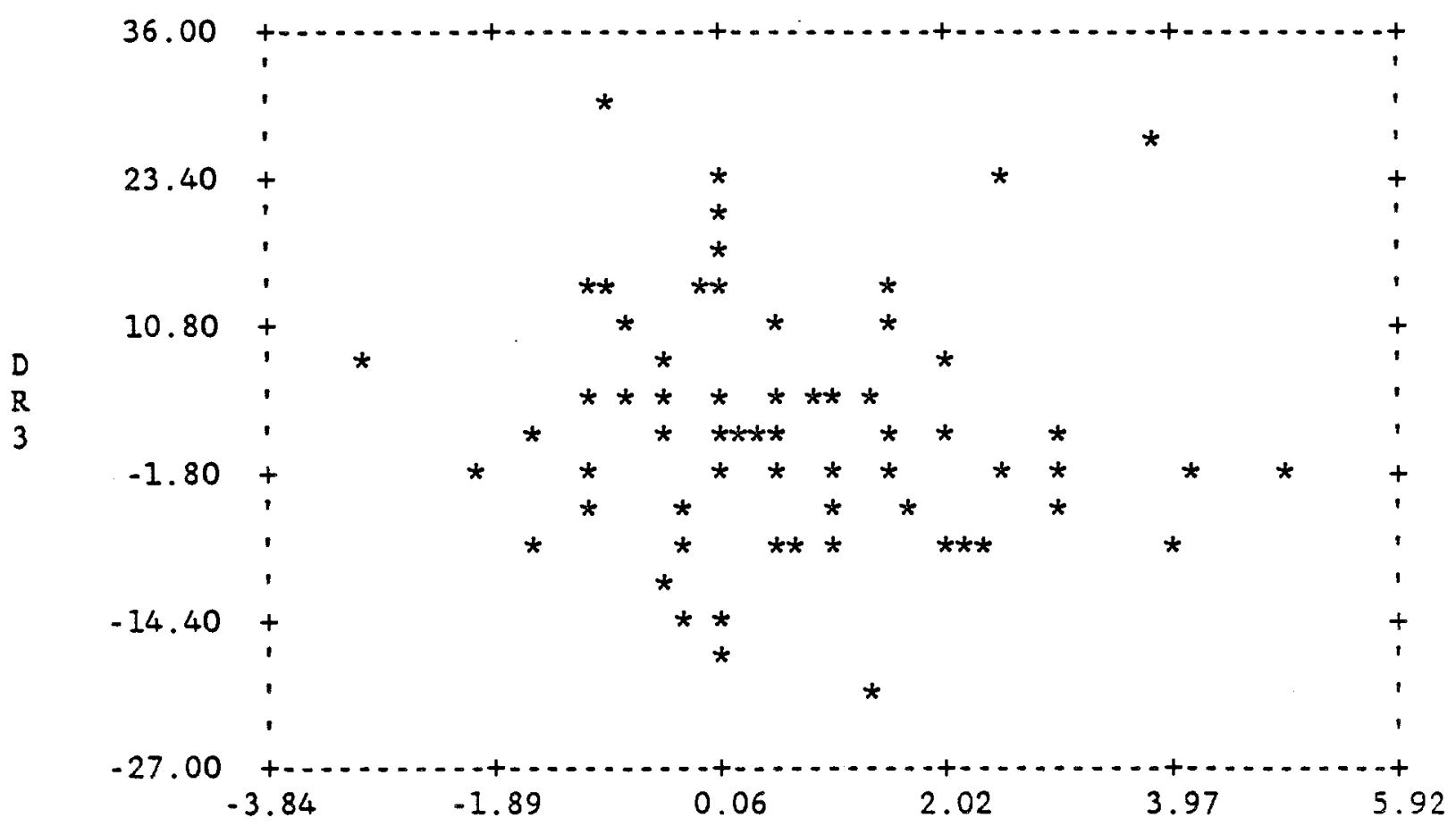

XMES

Note: DR3 is the change in the annualized interest rate on three-month U.S. Treasury bills from the close of the market on the day of a money supply announcement to the close of the market on the following day, measured in basis points. XMES is the expected change in the money supply announcement, based on the Money Market Services survey and measured in billions of dollars. A ' $*$ ' represents other, possibly multiple, observations. There are a total of 75 observations, representing weekly data from October 22, 1982 to March 29, 1984. The observation for February 14, 1983 has not been plotted since there appears to be a typographical error in the money supply revision announced on that date. 
other periods examined. ${ }^{14}$ The joint hypothesis that after October 1982 the coefficients $a_{1}$ and $a_{2}$ return to their pre-October 1979 values cannot be rejected using a 5 significance level. Closer inspection of the individual coefficients, however, indicates that there was a significant change in ${ }^{1}$, the only coefficient which is significantly different from zero in either period. The Chow test for testing the equality of $a_{1}$ in the pre-October 1979 and post-october 1982 periods is 5.66 (marginal significance level of .019).

Combining the results of testing within-sample and across-sample stability leads to the conclusion that from 1977 to 1984 the money supply amouncement-interest rate link is composed of three distinct relations. For the pre-October 1979 period no statistically significant, stable relation between money supply announcements and interest rates is apparent. ${ }^{15}$ For the October 1979 to October 1982 period there is a significant, positive association between unexpected money supply announcements and interest rate changes and a significant negative relation between expected money supply announcements and interest rate changes. For the post-October 1982 period, the positive link between unexpected money supply announcements and interest rate changes remains statistically significant but their impact diminishes. There is no significant link between expected money supply announcements and interest rates post-October 1982 .

V. Interest Rates, Monetary Base Announcements, and Data Revisions

The money supply is the product of the monetary base and the money multiplier. As previously explained, given the delays in releasing monetary data, money supply announcements convey new information about only the money 
multiplier. A natural question which arises from this observation is, do the weekly monetary base announcements provide any additional information relevant for interest rate determination? The evidence presented in this section shows that unexpected monetary base announcenents do have a statistically significant impact on interest rates during the period from October 1979 to October 1982. After October 1982, the effect of unexpected monetary base announcements diminishes and becomes statistically insignificant. Another question examined in this section is, do weekly announcements of money supply and monetary base revisions affect interest rates? It is shown that much previous research has constrained the interest rate impact of revisions and preliminary data announcements to be equal. While this constraint cannot be rejected, neither can the hypothesis that revision announcements have no effect on interest rates.

As mentioned in section II, weekly money supply announcements contain two sources of information. There is an announced change in the money supply, $D M_{t}=M_{t}-M_{t-1}$, and an announced revision of a previously reported money supply, $M R V_{t}=M I R_{t}-M_{t-1}$. The impact that these two announcements have on interest rates has been constrained in previous work. The most widely used constraint is that the impact of $\mathrm{DM}_{t}$ is equal in magnitude to the impact of $\mathrm{MRV}_{t}$, but is of the opposite sign. This constraint is used in previous sections since the series which was decomposed into an expected and unexpected component was $X M_{t}-D_{t}-M R V_{t}$. Another constraint which has been used is that $\mathrm{MRV}_{t}$ has no impact on interest rates, so that the series $\mathrm{DM}_{t}$ is decomposed into expected and unexpected components.

Imposing constraints on the way interest rates react to the two announcements is necessary if one wishes to measure expectations exclusively by survey data because only one survey series is available. Nevertheless, 
the constraints which have been imposed do not necessarily hold for the data being examined. A more general approach, one which would not impose these constraints, is desirable.

This more general approach is made operational in this section by decomposing both $\mathrm{DM}_{t}$ and $\mathrm{MRV}_{t}$ into their expected and unexpected components and relating interest rate changes to these four variables in an unconstrained manner. The decompositions are done in two ways. First, both $D M_{t}$ and $M_{R V}$ are decomposed into expected and unexpected components using linear regressions. The regressors are a constant, the survey measure of expectations, the most recent change in the money supply $\left(D M_{t-I}=M_{t-I}\right.$ $\left.M_{t-2}\right)$, revision in the money supply $\left(M R V_{t-1}-M L R_{t-1}-M_{t-2}\right)$, change in the monetary base $\left(D_{t-1}=B_{t-1}-B_{t-2}\right)$, and revision in the monetary base $\left(B_{t-I}=B L R_{t-I}-B_{t-2}\right)$ available before the announcement, the most recently available weekly change in the interest rate on three-month U.S. Treasury bills (DR3B $B_{t}=R 3 B_{t}-R 3 B_{t-I}$ ) and the spread between the interest rates on three- and six-month U.S. Treasury bills prior to the announcement (SPR ${ }_{t}=$ $\left.\mathrm{R} 6 \mathrm{~B}_{t}-\mathrm{R} 3 \mathrm{~B}_{t}\right)$. Thus, the survey information is supplemented by information from interest rates and past monetary announcements. The interest rate variables $D R 3 B_{t}$ and $S P R_{t}$ differ from the other regressors because they may contain useful information which becomes available after the survey is conducted butbefore the monetary announcements. The variables constructed from these regressions are $D_{M U R}$ (unexpected $\mathrm{DM}_{t}$ formed from regression), DMER $_{t}$ (expected $D M_{t}$ formed from regression), MRVUR $_{t}$, and MRVER . $^{\text {. }}$ The second decomposition is based on the assumption that the survey measure of expectations does not contain a forecast of the money supply revision, i.e. it is measuring expectations of $\mathrm{DM}_{t}$, not $\mathrm{XM}_{t}$. This assumption, which will be shown to be consistent with the data, implies that 
the variables DMUR $_{t}$ and $\mathrm{DMER}_{t}$ can be replaced by DMUS ${ }_{t}\left(\mathrm{DMUS}_{t}-\mathrm{DM}_{t}-\mathrm{XMES}_{t}\right.$, unexpected $\mathrm{DM}_{t}$ formed from the survey) and $\mathrm{XMES}_{t}$ (expected $\mathrm{DM}_{t}$ from the survey).

Before turning to the results which are based on these decompositions, issues involved with determining the impact that monetary base announcements may have on interest rates are considered. As described in section II, for the majority of dates on which money supply announcements are made, monetary base announcements are also made. These announcements are similar to the money supply announcements in that they two contain two parts, an announced change in the monetary base, $D B_{t}-B_{t}-B_{t-1}$, and an announced revision in the monetary base, $B R V_{t}-B L R_{t}-B_{t-1}$. With no survey measures of expectations concerning the monetary base announcements, $\mathrm{DB}_{t}$ and $\mathrm{BRV}_{t}$ have been decomposed using the same regression techniques used to decompose $\mathrm{DM}_{t}$ and $\mathbb{M R V}_{t}$. The variables formed are $\mathrm{DBUR}_{t}$ (unexpected changes in the announced monetary base formed from regression), $\mathrm{DBER}_{t}$ (expected changes in the announced monetary base formed from regression), $B$ RUR $t_{t}$ and BRVER $_{t}$.

The regression equations used to form the decompositions of the money supply and monetary base variables have been estimated separately for the October 1979 to October 1982 and the post October 1982 periods. Given limitations on data availability and the failure of the pre-October 1979 period to exhibit any significant relation between money supply announcements and interest rates, that period is dropped from subsequent analysis.

Table 2 presents the results of estimating equations for $\mathrm{DM}_{t}$ and $\mathrm{MRV}_{t}$. For purposes of comparison, results are also presented for $\mathrm{XM}_{t}$. The results for the $X M_{t}$ and $D M_{t}$ regressions are very similar, indicating that the survey series can be viewed as an equally good measure of the expected change in 
the announced money supply when that change does not include a revision as when it does. Although during the latter period lagged monetary base changes do contain information which is useful for predicting announced money supply changes that is not included in the survey forecast, the reported Fstatistics in the $\mathrm{DM}_{t}$ regressions show that the joint hypothesis that $a_{1}=1$ and the remaining $a_{i}=0$ cannot be rejected at standard significance levels in either time period. Survey responses thus appear to contain reasonably accurate forecasts of money supply announcements.

The information examined here has significant explanatory power for announcements of money supply revisions during the period from October 1979 to October $1982 .^{16}$ The F-statistic in the $M R V_{t}$ regression shows that the hypothesis that $a_{i}-0(i-1,7)$ is rejected at the 58 significance level. This implies that it is feasible to measure the separate impacts of the expected and unexpected money supply revisions on interest rates. In the post-October 1982 sample money supply revisions appear to be essentially unpredictable, raising the possibility that the impact of expected revisions is not identifiable from the data.

The results presented in Table 3 indicate that, in both periods examined, there is a predictable component to both the change in the announced monetary base and the monetary base revision.

The standard errors of the regressions presented in Tables 2 and 3 are also of interest. Those in Table 2 indicate that unexpected money supply changes and revisions have become less volatile post-October 1982 . Those in Table 3 do not show a similar finding for unexpected monetary base changes and revisions. Unexpected changes in the announced money supply are always more variable than unexpected changes in the announced base. For both money supply and monetary base announcements, unexpected revisions are less 
variable than the unexpected changes but the difference is more pronunced for the money supply.

Table 4 contains the results of relating interest rate changes to the expected and unexpected components of the four series $\mathrm{DM}_{t}, \mathrm{MRV}_{t}, \mathrm{DB}_{t}$ and $B R V_{t}$. Several of the results are worthy of note. ${ }^{17}$ First, during the October 1979 to October 1982 period, when announcement effects are most pronounced, unexpected increases in the announced monetary base significantly raise interest rates. ${ }^{18}$ Regardless of how money supply announcements are decomposed into an expected and an unexpected component, an unexpected increase in the announced monetary base of one billion dollars is estimated to increase the annualized interest rate on a three month U.S. Treasury bill by over thirteen and one half basis points. This estimated impact is greater in magnitude than the estimated impact of a similarly sized unexpected increase in the announced money supply, though the difference is not statistically significant at the 5 level. ${ }^{19}$ The strong impact that unexpected monetary base announcements have on interest rates exists only in the October 1979 to October 1982 period. There is no statistically significant impact of monetary base announcements after October 1982.

The estimated response of interest rates to unexpected changes in the announced money supply is not sensitive to allowing for effects of monetary base announcements, relaxing the constraint on the effects of money supply revisions, or augmenting survey data with additional information to form a regression-based measure of expected money supply announcements. An unexpected one billion dollar increase in the announced money supply is estimated to raise interest rates by between nine and one half and ten basis points in the October 1979 to October 1982 period and by between three and 
one half and four basis points post-October 1982. These effects are always statistically significant and are similar in magnitude to those in Table 1.20

Interest rates do not move significantly in response to announcements of unexpected money supply and monetary base revisions. However, the hypothesis that unexpected changes and revisions affect interest rates with equal magnitude and in opposite directions cannot be rejected at standard significance levels either. ${ }^{21}$ Either omitting announcements of revisions from the analysis or constraining their impact to be the same as that of announcements of preliminary monetary figures is compatible with the data.

When announcements are decomposed into an expected and unexpected component via regressions, no expected component of an announcement has a significant impact on interest rates in any time period. In contrast, the expected change in the announced money supply taken from the survey measure, XMES $_{t}$, does have a significant impact on interest rates during the October 1979 to October 1982 period. Thus, the modelling of expectations is important for determining if the expected component of announcements significantly affect interest rates but is not important for determining the significance of any other variables. 22

VI. The Predictive Ability of Unexpected Announcements for Future Money Supply and Monetary Base Changes

As shown in previous sections, interest rates move significantly in response to unanticipated money supply and monetary base announcements. In attempting to account for this effect of money supply announcements, one 
popular hypothesis contends that an increase in the unexpected component of the announced money supply raises expectations of money growth, thereby raising expected inflation and nominal interest rates. A competing hypothesis contends that an increase in the unexpected component of the announced money supply lowers expectations of money growth, raises expected future real interest rates, and thereby raises current real (and nominal) interest rates. In what follows, these are referred to as the "money supply expansion" and "money supply contraction" hypotheses. 23

Both these hypotheses envision unexpected announcements as conveying information about the future course of the money supply. In this section, the ability of unexpected money supply and monetary base announcements to predict subsequent changes in the money supply, as well as in the monetary base, is empirically examined.

It is shown that during the period from October 1979 to October 1982 , when monetary announcements had their largest impact on interest rates, unexpected money supply announcements had different predictive implications than did unexpected monetary base announcements. Unexpected increases in the announced money supply signalled increased money growth, but unexpected increases in the announced monetary base signalled decreased money growth. Also, while unexpected increases in both the announced monetary base and money supply are accompanied by higher base growth, this growth was larger and more permanent following base announcements. Since unexpected changes in the announced money supply and monetary base moved interest rates in the same direction and by the same magnitude during this time period, these findings cast doubt on the proposition that monetary announcements are moving interest rates solely by providing information about the subsequent behavior of the money supply or the monetary base. Changes in the predictive 
ability of unexpected money supply and monetary base announcements in October 1982 also appear problematical for this proposition.

Given the delay in publishing monetary data, a one billion dollar unexpected increase in the money supply announced in week $t$ raises the expected change in the money supply from week $t-2$ to $t-1$ by one billion dollars plus any change in the expected money supply revision to be announced in week $t+1$ that can be predicted by this announcement. 24 To the extent that the monetary base announcement made in week $t$ helps predict this revision, it contains additional information regarding the money supply change during this period. Both announcements may help predict money supply changes from week $t-1$ to any time in the future.

In order to examine these issues of prediction, the change in the money supply over three different horizons and the relevant money supply revision have been regressed on unexpected monetary announcements in week t. Table 5 reports the results from estimating these regressions. The dependent variable $M R V_{t+1}=M L R_{t+1}-M_{t}$ is the money supply revision announced in week $t+1$. DMFO $t_{t}=M L R_{t+2}-M_{t}, D M F 4_{t}=M L R_{t+6}-M_{t}$ and DMF13 $=M L R_{t+15}-M_{t}$ measure the sum of this revision and the change in the money supply (including revision) from week $t-1$ to week $t$, week $t-1$ to one month after the announcement and week $t-1$ to one quarter after the announcement, respectively. The independent variables are the unexpected announcements DMUS $_{t}$ and DBUR $_{t}$. Similar results apply if DMUS $_{t}$ is replaced by XMUS ${ }_{t}$, DMUR or $X_{T}$. $^{\prime}$

The evidence for the October 1979 to October 1982 sample is that a one billion dollar surprise increase in the money supply announced in week $t$ predicts that the money supply change from week $t-2$ to week $t$ will be higher by 0.60 billion dollars $(0.60=1.0-0.40)$, a statistically significant 
increase. This figure is the net result of the initial 1.0 billion dollar increase from week $t-2$ to week $t-1$ being revised to a 1.07 billion dollar increase and followed by a reduction of 0.47 billion dollars in the money supply from week $t-1$ to $t$, a reduction which only partially offsets the initial increase. The estimated $a_{1}$ coefficients in the DMF4 and DMF13 regressions are not significantly different from zero but are significantly different from minus one. ${ }^{25}$ Thus, for the one-month and one-quarter horizons, one cannot reject the hypothesis that there is no offset of the initial increase in the money supply but can reject the hypothesis that there is a full offset of the initial increase. An unexpected increase in the money supply announced in week $t$ signals a permanently higher money supply beginning with week $t-1$ and, accordingly, a higher growth rate from week t-2 to all dates in the future.

In contrast, during the October 1979 to October 1982 period an unexpected increase in the monetary base announced in week $t$ predicts a lower money supply in the future and lower growth rates from week $t-2$ forward. A 1.0 billion dollar surprise increase in the monetary base predicts a significant reduction of 1.12 billion dollars in the money supply change from week $t-2$ to $t$, with reductions of 1.41 and 2.06 billion dollars predicted for the horizons of one month and one quarter. Despite the significance of these reductions for the longer horizons, the t-statistics in square brackets beneath the coefficients indicate that no significant changes are predicted from week $t$ to the future. The significant money supply contraction that follows an increase in the unexpected monetary base announcement occurs only from week $t-1$ to week $t$.

The results reported in Table 5 show that no major change is apparent in the predictive ability of money supply announcements for money supply 
behavior after October 1982. The parameter estimates suggest that, as before, unexpected increases in the announced money supply signal higher money growth rates from week $t-2$ to the future. Given the imprecision of the estimated parameters, however, the evidence is less conclusive. Neither the hypothesis that there is no offset following an unexpected increase in the announced money supply nor the hypothesis that such an increase is fully offset can be rejected at the $5 \%$ signficance level for horizons beyond the announcement date.

For the post-October 1982 period, unexpected increases in monetary base announcements predict a money supply reduction from week $t-1$ to week $t$ but predict money supply expansion for the horizons of one month and one quarter. These predicted expansions and the lack of any significant predictive power are in sharp contrast to the results for the October 1979 to October 1982 period, when unexpected increases in the monetary base significantly predict money supply reductions.

Taken together, the findings reported in Tables 4 and 5 lead to mixed conclusions about the empirical accuracy of the the hypotheses discussed in the first paragraph of this section. The "money supply contraction" hypothesis is supported by the significant predictive ability of unexpected monetary base announcements for money supply changes and the significant effect of these announcements on interest rates during the October 1979 to October 1982 period. The changes to a lack of significant predictive ability and the absence of a significant interest rate effect for monetary base announcements in the post-October 1982 period is also consistent with the hypothesis. However, the finding that unexpected increases in the announced money supply both raise interest rates and signal higher money growth in all periods contradicts the hypothesis. While this latter result does provide 
support for the "money supply expansion" hypothesis, the findings previously discussed for monetary base announcements during the October 1979 to October 1982 period conflict with it. The "money supply expansion" hypothesis is also in apparent conflict with the reduction in the impact of unexpected money supply announcements on interest rates after October 1982 and the lack of a noticeable change in the predictive ability of these announcements for subsequent money supply behavior.

The failure of these hypotheses to fully account for the interest rate response to unexpected money supply and monetary base announcements indicates that the response is not attributable to only the arrival of new information about the behavior of the money supply. Unexpected monetary announcements must be conveying information about other variables relevant for interest rate determination. The monetary base may be such a variable. Accordingly, Table 6 provides evidence on the predictive ability of unexpected monetary announcements for future monetary base changes. This evidence also supplements'the evidence in Table 5 by indicating how the money supply changes predicted by unexpected monetary announcements occur, i.e. whether through changes in the monetary base and/or the money multiplier.

A one billion dollar unexpected increase in the monetary base announcement in week $t$ raises the expected change in the base from week $t-1$ to $t$ by one billion dollars plus any change it can predict for the revision to be announced in week $t+1 .{ }^{26}$ Money supply announcements can help predict changes in the monetary base from week $t-1$ to week $t$ only if they can predict the base revision announced in week $t+1$. Both announcements may help predict monetary base changes from week $t$ to any time in the future. 
Table 6 contains the results of regressing the relevant monetary base revision and subsequent base changes on unexpected monetary announcements. $B R V_{t+1}=B L R_{t+1}-B_{t}$ is the monetary base revision announced in week $t+1$. $D B F 1_{t}=B L R_{t+2}-B_{t}, D B F 4_{t}=B L R_{t+5}-B_{t}$ and $D B F 13_{t}=B L R_{t+14}-B_{t}$ measure the sum of this revision and the change in the base (including revision) from week $t$ to week $t+1$, week $t$ to one month after the announcement and week to one quarter after the announcement, respectively. The only results indicating that unexpected money supply announcements have significant predictive power for monetary base behavior are for the period October 1979 to October 1982, when an increase in the unexpected money supply announcement in week $t$ predicts an increase in the monetary base change from week $t$ to $t+1$. However, there is no significant prediction of a change in the base for horizons of one month or one quarter and the size of the estimated $a_{1}$ coefficient in the DBF4 regression (and the t-statistic appearing in square brackets below it) suggests that this initial increase in the base is offset within a month.

As regards the predictive ability of unexpected monetary base announcements, the evidence for the October 1979 to October 1982 sample is that a 1.0 billion dollar surprise increase in the base announced in week $t$ predicts that the monetary base change from week $t-1$ to $t+1$ will be statistically significantly higher by 0.31 billion dollars $(0.31=1.0$ 0.69 ). The predicted reduction of 0.69 billion dollars, which only partially offsets the initial increase, is composed of a -0.20 billion dollar monetary base revision announced at time $t+1$ and a -0.49 billion dollar change in the base from week $t$ to $t+1$. The predicted monetary base changes from week $t-1$ to one month and one quarter after the announcement are also higher, by 0.32 and 0.20 billion dollars respectively. The similarity between the magnitude 
of these changes and the change from week $t-1$ to $t+1$ suggests that no important movements in the monetary base are predicted after week $t+1$. For this sample, an unexpected increase in the monetary base announced in week $t$ signals a higher base during all weeks from $t$ into the future and, accordingly, a higher growth rate from week $t-1$ to all dates in the future.

For the period post-October 1982, an unexpected increase in the base announced in week $t$ is again followed by significant offsetting changes. The hypothesis that these changes fully offset the increase cannot be rejected at any of the horizons considered using a 58 significance level. However, for the one month and three month horizons the point estimates indicate only a partial offset. In summary, an unexpected increase in the announced monetary base provides evidence of a statistically insignificant increase in base growth from week $t-1$ to the future.

Taken together, does the evidence in Tables 4 and 6 suggest that the informational content of unexpected monetary announcements for monetary base changes is an important factor for explaining why these announcements affect interest rates? For money supply announcements, the answer is quite clearly no. These announcements generally have no predictive power for monetary base changes, yet they do have a significant impact on interest rates. For monetary base announcements the answer is less clear. During the October 1979 to October 1982 period, an unexpected increase in the announced monetary base significantly raises interest rates and signals a permanently higher level of the base, consistent with a "monetary base expansion" hypothesis. After October 1982, the interest rate effect of unexpected monetary base announcements diminishes and becomes insignificant while it is unclear whether there is a reduction in the size of the monetary base change predicted by these announcements. 
Combining the results reported in Tables 5 and 6 provides evidence on how the predictions of money supply changes contained in unexpected monetary announcements are divided into predictions of subsequent changes in the money multiplier and the monetary base. For both samples examined, an unexpected increase in the money supply announcement made in week $t$ predicts a higher money supply for weeks $t-1, t, t+4$ and $t+13$, significantly so in all but one case. Given that information about the monetary base in weeks $t-1$ and $t$ is available in week $t$ and that unexpected money supply announcements have no significant predictive power for the monetary base over the one month or one quarter horizons, the increase in the money supply predicted for these weeks is due only to information about higher money multipliers. Money supply announcements are not only providing new information solely about previous money multipliers, but their predictions of subsequent money supply changes are limited to predictions about subsequent money multipliers.

Unexpected monetary base announcements have significant predictive power for subsequent money supply behavior only from October 1979 to October 1982. During this period an unexpected monetary base increase announced in week $t$ signals a lower money supply and a higher monetary base for weeks $t$, $t+4$ and $t+13$. Thus, the decrease in the money supply predicted by these announcements is reflecting predictions of changes both in the multiplier and in the base, with the multiplier changes being more important. 
VII. The Impact of Monetary Announcements on Term-Structure Premia

This section provides evidence that several of the new empirical regularities reported in previous sections for the interest rate on threemonth U.S. Treasury bills also carry over to the longer-term interest rates on six- and twelve-month U.S. Treasury bills. Since these longer-term interest rates can be decomposed into a current short-term rate, expected future short-term rates and term premia, it is useful to determine the specific channel that gives rise to the interest rate effects of unanticipated monetary announcements. The results of this section indicate that both unexpected money supply and monetary base announcements are affecting six- and twelve-month interest rates through their impact on current and expected future three-month rates, with no impact on term premia.

The results presented in Tables 7 and 8 , for six- and twelve-month interest rates respectively, show many similarities to those presented in Table 4 for the three-month interest rate. During the October 1979 to October 1982 period, unexpected increases in both the announced money supply and monetary base significantly raise these longer-term interest rates and the hypothesis that the impact of an unexpected monetary base announcement is equal to the impact of an unexpected money supply announcement of the same magnitude cannot be rejected at standard significance levels. ${ }^{27}$ PostOctober 1982 only unexpected money supply announcements have a significant effect. Expected announcements significantly affect six- and twelve-month interest rates only if measured by the Money Market Services survey; although in contrast to the results for three-month interest rates, these effects are significant both before and after October 1982 . Unexpected 
monetary revisions do not have a significant impact on interest rates in either sample.

Are the effects of unexpected monetary announcements on the longer-term interest rates that are documented in Tables 7 and 8 capturing the effect of these announcements on current short-term interest rates, on expected future short-term interest rates and/or on term premia? Specifically, consider the following equations which link the six-month interest rate to current and expected future three-month interest rates and a term premium:

$$
\begin{aligned}
& R 6 B_{t}=.5 * R 3 B_{t}+.5 *_{b, t}{ }^{R 3 B} B_{t+13}+T^{T} 6 B_{t} \\
& R 6 A_{t}=.5 * R 3 A_{t}+.5 *{ }_{a, t}{ }^{R 3 A_{t+13}}+\mathrm{TP} \mathrm{A}_{t}
\end{aligned}
$$

where $R 3 B_{t}$ and $R 3 A_{t}$ are the three-month interest rates before and after the announcements in week $t$ (similarly for $R 6 B_{t}$ and $R 6 A_{t}$ ), $b, t^{R 3 B} B_{t+13}$ is the expectation of $R 3 B_{t+13}$ before the announcement in week $t, a, t^{R 3 A} t_{t+13}$ is the expectation of $R 3 A_{t+13}$ after the announcement in week $t$, and TP6B and TP6A are the term premia defined by the two equations. Subtracting the first equation from the second yields

$$
{ }^{D R 6}{ }_{t}=D T P 6_{t}+.5 * D R 3_{t}+.5 *\left({ }_{a, t}{ }^{R 3 A}{ }_{t+13}-b, t{ }_{t+13}\right)
$$

where DTP6 $t=\mathrm{TP}_{t} \mathrm{~A}_{t}-\mathrm{TP6B} \mathrm{H}_{t}$. The corresponding equation for the change in the twelve-month interest rate is

$$
\begin{aligned}
& D R 12=D T P 12_{t}+.25 * D R 3{ }_{t}+.25 *\left({ }_{a}, t^{R 3 A} t+13-b, t{ }^{R 3 B}{ }_{t+13}\right) \\
& +.25 *\left(a, t^{R 3 A} t+26^{-} b, t^{R 3 B} t+26^{2}\right)+.25 *\left(a, t^{R 3 A}{ }_{t+39^{-}} b, t^{R 3 B} t+39\right) \text {. }
\end{aligned}
$$

The arrival of new information contained in monetary announcements can affect ${ }^{D R}{ }_{t}$ and ${ }^{D R 12}{ }_{t}$ through its effect on any or a11 of the variables on the right-hand-side of the above equations.

A test of the hypothesis that unexpected monetary announcements move these longer-term interest rates solely by affecting the current three-month rate, i.e. that they have no impact on term premia or on expected future 
three-month interest rates, can be conducted using results from regressions

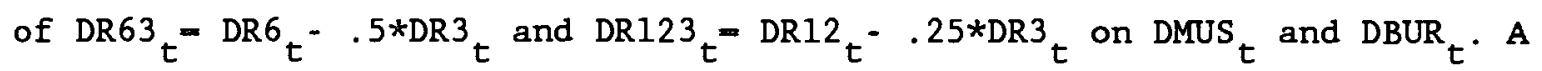
finding of significant coefficients on these regressors indicates rejection of the hypothesis. Table 9 reports the results of estimating these regressions. During the period from October 1979 to October 1982, the coefficients on DMUS $t_{t}$ and $\mathrm{DBUR}_{t}$ in the ${ }^{\mathrm{DR} 6} \mathrm{t}^{-} .5 * \mathrm{DR}{ }_{t}$ regression and the coefficient on DMUS $t_{t}$ in the DRl2 $t^{-} .25 * D R 3{ }_{t}$ regression significantly differ from zero at the 58 level. The coefficient on DMUS $_{t}$ is significant in both regresssions after October 1982. Thus, the significant response of six- and twelve month interest rates to unexpected monetary announcements is reflecting a movement in expected future three-month rates and/or termstructure premia.

To examine whether movements in term-structure premia are significantly responding to unexpected monetary announcements, the changes in the six- and twelve month premia (DTP6 ${ }_{t}$ and DTP12 ${ }_{t}$ ) are postulated to be linear functions of DMUS ${ }_{t}$ and DBUR $_{t}$. In addition, the terms $a, t^{R 3 A}{ }_{t+j}(j=13,26$ and 39$)$ are expressed as the sum of the actual value $R 3 A_{t+j}$ and a forecast error $e_{j, t}$. Substituting these specifications into the above equations for $\mathrm{DR}_{t}$ and DR12 $t$, and moving all observable variables with known coefficients to the left-hand-side, yields

$$
\text { PREMJ }_{t}=a_{0}+a_{1} * \text { DMUS }_{t}+a_{2} * \text { DBUR }_{t}+e J_{t}, \quad J=6,12
$$

where PREM $_{t}=D R 6_{t}-.5 * D R 3_{t^{-}} .5 * R 3 A_{t+13}, P^{P R E M 12}{ }_{t}=D R 12_{t}-.25 * D R 3{ }_{t}$

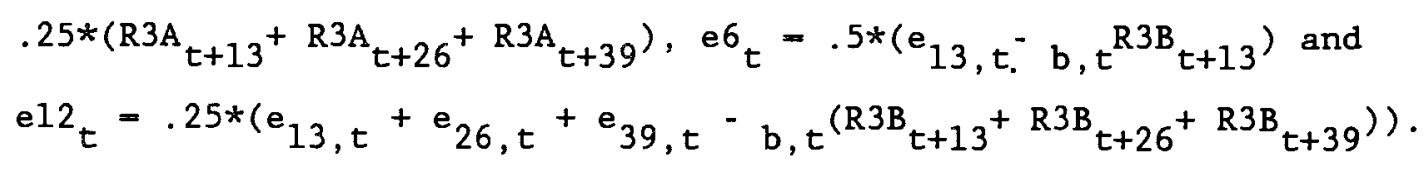
Under the assumption that expectations of future interest rates are formed rationally, estimation of these equations by ordinary least squares gives consistent estimates of the unknown parameters $a_{i} \cdot{ }^{28}$ A finding that 
the coefficients on DMUS ${ }_{t}$ or DBUR $_{t}$ are significantly different from zero indicates that term-structure premia are affected by unexpected monetary announcements. If the effect of these announcements on the longer-term interest rates is solely due to their impact on current and expected future three-month interest rates, then (except for sampling error) these coefficients will not be significantly different from zero.

Table 10 provides estimates of the effects that unexpected monetary announcements have on six- and twelve-month term-structure premia. Unexpected increases in the announced money supply are estimated to lower both term premia in the October 1979 to October 1982 period but raise these premia after October 1982. Unexpected increases in the announced monetary base are estimated to increase both premia during the period from October 1979 to October 1982, the only period when these announcements have a significant impact on interest rates. However, none of the coefficients reported in Table 10 are significantly different from zero. Unexpected monetary announcements appear to move six-and twelve interest rates because of their impact on both current and three-month interest rates, but not because of their impact on term-structure premia.

VIII. CONCLUDING REMARKS

This paper contains the results from an econometric investigation of the link between interest rates, money supply announcements and monetary base announcements. A new set of empirical regularities regarding the effects of these announcements on interest rates, their predictive ability for the subsequent behavior of the money supply and monetary base, and their 
effects on term-structure premia has been presented. Since the main findings have been summarized in the introductory section, we conclude by discussing some of their implications for future research.

It has been shown that interest rates respond significantly not only to announcements of the Ml money supply, but also to the announcements of the monetary base. Since the Federal Reserve releases weekly information on a variety of other monetary aggregates, a more complete characterization of the monetary announcements-interest rate link can be obtained by investigating the response of interest rates to these other announcements. For example, the diminished magnitude of the impact that M1 announcements have after October 1982 makes it interesting to know if announcements concerning M2 or M3 are of increased importance for interest rate determination after this date. In addition, it would be useful to examine the effects of individual components of the announced monetary aggregates on interest rates, e.g. checkable deposits, currency, borrowed reserves, and nonborrowed reserves.

The methodology used in this paper to evaluate the ability of alternative hypotheses to explain the link between monetary announcements and interest rates is straightforward. It entails examining how the information contained in the unexpected announcements can be used to predict future values of critical variables. Since the evidence presented here casts doubt on the proposition that unexpected monetary announcements are affecting interest rates solely by providing information about the subsequent behavior of the money supply or the monetary base, it would be worthwhile to investigate whether these announcements contain information concerning other variables relevant for interest rate determination. 
Possible candidates are future inflation, real interest rates and real economic activity.

In terms of future theoretical research, the empirical regularities reported here place restrictions on the class of models that can be used to explain the observed monetary announcements-interest rate link. The findings that new information about both the money multiplier and the monetary base have a significant impact on interest rates and that the magnitudes and significance of these impacts are different when different operating procedures are used by the Federal Reserve, are examples of phenomena that a complete theoretical explanation must account for. 
FOOTNOTES

1. See Cornell (1983a,1983b,1985), Engel and Frankel (1984), Falk and Orazem (1985), Grossman (1981), Hardouvelis (1984), Judd (1984), Loeys (1985), Roley $(1982,1983)$, Roley and Troll (1983), Roley and Walsh $(1983,1984)$, Shiller, Campbell and Schoenholtz (1983), and Urich and Wachtel (1981).

2. Admittedly, the correct procedure for this decomposition is not immediately obvious given the vagueness of the survey question and the fact that the money supply announcement contains two pieces of information, $M_{t}$ and $M L R_{t}$. The survey asks for the respondent's expected change in the money supply without specifying what base level should be used. That is, no mention is made of whether the respondent should forecast $M_{t}-M_{t-1}$ or $M_{t}-M L R_{t}$. If respondents are including a prediction of the monetary revision in their forecast of the change in the money supply, the correct decomposition is $\mathrm{XMES}_{t}$ and $\left(\mathrm{M}_{t}-\mathrm{MLR}_{t}\right)-\mathrm{XMES}_{t}$. If respondents are not forecasting the revision, the correct decomposition is $X M E S S_{t}$ and $\left(M_{t}-M_{t-1}\right)-X_{t}$. Both decompositions have been used in the past, but the majority of researchers assume that respondents are forecasting the revision. Accordingly, in this section the unexpected change in the announced money supply is defined to be XMUS $_{t}=\left(M_{t}-M L R_{t}\right)-X_{t}$. An analysis of whether revisions in the money supply are predictable and are included in respondents forecasts is taken up section $V$.

3. Time periods A.1 and B.1 have been estimated separately since previous research has shown that the October 1979 change in monetary policy, away from interest rate targeting and towards monetary aggregates targeting, has affected the money supply announcement-interest rate relation. We subdivide the post-October 1979 period because of another change in monetary policy in October 1982, when the Federal Reserve returned, at least partially, to interest rate targeting.

4. Because some of the money supply announcements are on Thursdays and others are on Fridays, DR3 measures an interest rate change which is sometimes from Thursday to Friday and sometimes from Friday to Monday. This, along with the fact that announcements do not always take place on 
the scheduled day, led us to test for a day-of-the-week effect in our sample. There was no evidence of such an effect.

5. These results are in conformity with those reported in studies using similar specifications. For example Roley and Troll (1983) report the impact of a one billion dollar surprise in the announced money supply on the interest rate of a three-month U.S. Treasury bill to be 1.58 basis points in the pre-October 1979 period and 10.38 basis points in the October 1979 to October 1982 period. Shiller, Campbell and Schoenholtz (1983) estimate the impact to be 9.88 in the period from February 1980 to February 1983. Studies which measure the unexpected money supply announcement in percentage rather than absolute changes are also similar in that they indicate a positive, statistically significant impact both pre-October 1979 and from October 1979 to October 1982, with the magnitude of the impact being noticeably larger in the latter period. See for example Cornell (1985), Falk and Orazem (1985), and Judd (1984). Judd (1984) and Loeys (1985) present evidence that the impact diminshes after October 1982. Work by Grossman (1981) and Roley $(1982,1983)$ on the pre-October 1979 and October 1979 to October 1982 periods differs from this study and the studies mentioned above because they measure the change in interest rates over an hour and a half interval rather than a one day interval. In terms of the sign and significance of the estimated relations, their results match those of Table 1 .

6. These results are also in general agreement with those reported in other studies. Direct comparison of point estimates is not possible since studies which measure money supply announcements as absolute changes, such as Roley and Troll (1983) and Shiller, Campbell and Schoenholtz (1983), do not report an estimate of the impact of the expected component of the announcement. However, studies which measure money supply announcements in percentage terms, such as Cornel1 (1985) and Falk and Orazem (1985), report the impact of the expected component of the money supply announcement on the interest rate for a three-month U.S. Treasury bill to be negative both pre-October 1979 and from October 1979 to October 1982, but to be statistically insignificant in the earlier period. For the latter period the results of Falk and 
Orazem (1985) indicate that the impact is statistically significant while those of Cornell (1985) indicate insignificance. Studies which measure interest rate changes over an hour and a half horizon also report results which are similar to those in Table 1. That is, Grossman (1981) and Roley $(1982,1983)$ find that pre-October 1979 expected money supply announcements have a negative but insignificant impact on interest rates, and Roley $(1982,1983)$ finds that from February 1980 to October 1982 this impact is negative and significant.

7. The null hypothesis is that the coefficients $a_{1}$ and $a_{2}$ are equal in the first and second halves of the sample. Chow tests of the stability of the coefficients $a_{0}, a_{1}$, and $a_{2}$ and of the coefficient $a_{1}$ alone were also computed. These tests lead to the same conclusions as those reported in Table 1 . In all tests, the coefficients that are not being tested for stability are left unconstrained.

8. The Goldfeld-Quandt test for heteroskedasticity is described in Johnston (1972), pages 218-19. The test involves ordering the observations in a manner which, a priori, should lead to increasing variance. Several observations are dropped from the middle of the sample, a separate regression is fit to the first and last sets of observations and the ratio of the two sums of squared residuals is formed. Under the null hypothesis of no heteroskedasticity, the asymptotic distribution of this statistic is the F-distribution with $n_{1}-k$ and $n_{2}-k$ degrees of freedom, where $n_{1}$ and $n_{2}$ are the number of observations in the first and last samples and $k$ is the number of explanatory variables. The test statistics reported in Table 1 use the first and last 39 observations from sample A.1, the first and last 58 from sample B.1, the first and last 28 from sample C.1, the first and last 38 from sample A.2, and the first and last 31 from sample A.3.

9. If XMUS and XMES are orthogonal (uncorrelated), the OLS regression coefficients on these variables can be obtained in the bivariate regressions of DR3 on a constant and XMUS and DR3 on a constant and XMES .

10. Testing for the stability of the coefficients $a_{1}$ and $a_{2}$ separately confirms the fact that the Chow test reported in Table 1 is reflecting primarily instability in $a_{1}$. The $F$-test for testing stability of $a_{1}$ is 
7.35 (marginal significance level equal to .008) and for testing the stability of $a_{2}$ is 0.44 (marginal significance level equal to .51).

11. The date of March 30, 1978 results from dropping the first one fourth of the pre-October 1979 sample. This date was arrived at as follows. The two regressions estimated for the construction of the $G-Q$ test reported in Table 1 indicated that the variance of the regression error was larger in the latter part of the pre-October 1979 sample. Splitting these samples in half indicated no significant change in the size of the error variance in the second half but a significant change of the error variance in the first half. Next, we tested for a constant error variance in the last three-fourths of the pre-October 1979 sample and failed to reject this hypothesis.

12. For the pre-October 1979 period, Grossman (1981) estimates that a one billion dollar positive surprise in the money supply announcement raises the interest rate on a three-month U.S. Treasury bill by 0.83 points, while Roley $(1982,1983)$ reports estimates from 0.65 to 0.78 bas is points. In contrast to our finding in sample A.2, Grossman (1981) and Roley $(1982,1983)$ find this effect to be statistically significantly different from zero. This difference is explainable by their use of a shorter interval for measuring the interest rate change, which results in more precise estimates. Roley (1983) also reports test statistics indicating a lack of coefficient instability and of heteroskedasticity in the pre-October 1979 sample.

13. So as not to constrain the variances of the regression errors to be equal across samples, the tests have been conducted using weighted least squares estimates. The weights are based on estimates of the regression error variances obtained from the estimated equations reported in Table 1 .

14. Although it is generally recognized that October 1979 marks a change in the money supply announcement-interest rate link, with the exception of Roley (1983), previous work has not formally documented the significance of this change. Loeys (1985) tests for the significance of changes in the money supply announcement-interest rate relation but the results are hard to interpret for two reasons. First, apparently no adjustment is made for the heteroskedasticity across sample periods. Second, the breakpoints used in the Chow tests are selected so as to maximize the 
probability of finding a significant break. Quandt (1960) shows that this procedure is not asymptotically valid.

15. As described in footnote 12, the relatively small impact of unexpected announcements has been estimated to be statistically significant when interest rate changes are measured over a shorter time interval than the one day interval used here.

16. The issue of whether revisions of the originally published money supply data are predictable or not has also been addressed by Mankiw, Runkle and Shapiro (1984). Though their data and approach are different, they reach the same basic conclusion -- at the time of its release, the originally published estimate is not the optimal available predictor of the true money supply.

17. Given that for the post-October 1982 period the F-test reported in Table 2 does not reject the hypothesis that money supply revisions are unpredictable, the equations of Table 4 have also been estimated for this sample replacing MRVUR and MRVER with MRV. None of the results reported below are affected by this change.

18. The standard errors of the estimated parameters reported in Table 4, and throughout the paper where appropriate, have been adjusted to reflect the use of a two-step procedure, i.e. first using a regression to form the expectations and then using these expectations as regressors. See Murphy and Tope1 (1985) and Pagan (1984).

19. For example, the Wald statistic for testing that DBUR and DMUR have the same impact on interest rates is 0.55 , which has a marginal significance level of .46 .

20. Data availability has necessitated reducing the sample sizes used for Table 4 from those used for Table 1; for details, see the the appendix. When the equations of Table 1 are estimated for the smaller samples, the coefficients on XMUS $t$ and XMES $t$ are 9.24 and -6.76 for the period October 1979 to October 1982 ( $\mathrm{SER}=35.13, \overline{\mathrm{R}}^{2}=.25$, and D.W. $=1.66)$, and 3.36 and -1.16 for the post-October 1982 period $\left(\right.$ SER $=8.16, \bar{R}^{2}=.39$, and D.W. -1.93$)$.

21. For example, the Wald statistic for testing that the coefficient on DMUR is equal in magnitude but opposite in sign to the coefficient on MRVUR is .02 (marginal significance level of .89) in the earlier period and .46 (marginal significance level of .50) in the latter period. In these 
regressions the Wald statistic for testing that the coefficient on DBUR is equal in magnitude but opposite in sign to the coefficient on BRVUR is 3.13 (marginal significance level of .08) in the earlier period and 1.99 (marginal significance level of .16) in the latter period.

22. This result conforms with Roley (1983) for the period February 1980 to October 1982 (the only period he examines), despite some differences in the construction of the augmented expectations.

23. These two hypotheses have also been referred to as the "expected inflation" and the "policy anticipations" hypotheses. Because these names are slightly misleading, in that both hypotheses implicitly incorporate some policy anticipations, we use different names. For a review of these, and other, hypotheses see Cornel1(1983b).

24. DMUS ${ }_{t}$ should not alter expectations of money supply changes from week $t-j$ to $t-2(j=3,4, \ldots)$ because the new information it contains is information about the money supply in week $t-1$. Expected money supply changes from week $t-2$ to $t+h(h=-1,0,1, \ldots)$ are the only ones that can be affected.

25. Notice that the amount of serial correlation in the regression residuals increases as the forecasts become for longer horizons. This is to be expected since a longer horizon indicates overlapping forecasts. Depite this serial correlation, the standard errors which are typically reported for the estimated coefficients on the unexpected announcements are valid, i.e. they are consistent estimates. This follows from the fact that the unexpected announcements are serially uncorrelated.

26. DBUR $t$ should not alter expectations of monetary base changes from week $t-j$ to $t-1(j=2,3, \ldots)$ because the new information it contains is information about the base in week $t$. Expected monetary base changes from week $t-1$ to $t+h(h=0,1, \ldots)$ are the only ones that can be affected.

27. For the six-month interest rate, the Wald statistic for testing that DBUR and DMUR have the same impact on interest rates is .40 (marginal significance level of .53). For the twelve-month interest rate the Wald statistic is .00 .

28. Of primary concern here is a possible correlation between the regressors and the regression error. If expectations are formed rationally, the regressors DMUS $t_{t}$ and DBUR $_{t}$ are errors from optimally formed forecasts and are thus uncorrelated with ${ }_{b, t} t_{t+j}(j=13,26,39)$, information 
available at the time the forecasts are made. The remaining components of the regression error terms are uncorrelated with the regressors DMUS $t$ and DBUR $_{t}$ under the assumption of rational expectations because they are the forecast errors $e_{j, t}(j-13,26,39)$, forecast errors based on an information set that includes the regressors. The ability to obtain consistent estimates via ordinary least squares explains why the terms $b, t^{R 3 B}{ }_{t+j}(j=13,26,39)$ are not treated in the same way as $a, t^{R 3 A_{t+j}}$, i.e. are not expressed as the sum of the actual value and a forecast error. Recall that the expectations $b, t^{R 3 B}{ }_{t+j}$ are made before the announcements in week $t$ and thus the forecast error associated with them

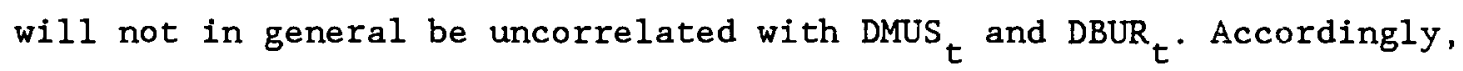
ordinary least squares estimation gives inconsistent estimates if the regression error contains these forecast errors. 
Description of Sample Periods for the Regressions in Tables $1-10$

The pre-October 1979 sample period A.1 contains 106 observations, covering September 29, 1977 to October 4, 1979. The pre-October 1979 sample A. 2 contains 104 observations, dropping the two influential observations shown in Figure 1. Sample A.3 contains 78 observations, dropping the influential observations and observations before March 30, 1978.

The October 1979 to October 1982 sample period B.1 has 156 observations, covering October 11, 1979 to October 15, 1982. Two of the 158 possible observations are dropped because of changes in the definition of money used in the announcement. The October 1979 to October 1982 sample B.2 has 134 observations. The loss of 22 additional observations is due to one of the following reasons: (i) a change in the definition of money, (ii) the money supply and monetary base announcements were not released on the same day, (iii) an apparent typographical error in the published value of revised monetary base, (iv) no monetary base announcement was made, ( $v$ ) monetary base announcements contain benchmark revisions, (vi) variables are calculated using only data which was released after the October 1979 shift in Federal Reserve policy. The sample periods B.3 and B.4 contain 114 and 103 observations. This reduction is necessary because these samples are used when the change in the money supply and monetary base over horizons as long as one quarter are required. More observations are dropped for the sample B.4 than for B.3 since the change in the base cannot span the weeks in which a benchmark revision is announced. Sample B.5 has 99 observations, with 35 observations dropped from sample B.2 because this sample is used when the three-month interest rate nine months hence is required.

The post-October 1982 sample period C.I contains 75 observations covering October 22, 1982 to March 29, 1984. One of the 76 possible observations has been dropped due to an apparent typographical error in the announced money supply revision. Sample C.2 has 60 observations. The loss of 15 observations is due to one of the following reasons: (i) an apparent typographical error in the published value of revised money supply, (ii) the money supply and monetary base announcements were not released on the same day, (iii) no monetary base announcement was made, (iv) monetary base announcements contain benchmark revisions, (v) variables are calculated using only data which was released after the October 1982 shift in Federal Reserve policy. Samples C.3 and C.4 contain 51 and 33 observations, while sample C. 5 has 33 observations (though not the same 33 as sample C.4). The reasons for dropping observations when going from sample C.2 to samples C.3, C. 4 and C.5 are the same as those for dropping observations when going from sample B.2 to samples B.3, B.4 and B. 5 . 


\section{REFERENCES}

Cornel1, Bradford (1983a) "Money Supply Announcements and Interest Rates: Another View," Journal of Business 56 (January), 1-24

Cornel1, Bradford (1983b) "The Money Supply Announcements Puzzle: Review and Interpretation," American Economic Review 73 (September), 644-57

Cornell, Bradford (1985) "The Money Supply Announcements Puzzle: Reply," American Economic Review 75 (June), 565-66

Engel, Charles and Jeffrey A. Frankel (1984) "Why Money Supply Announcements Move Interest Rates: An Answer from the Foreign Exchange Market," Journal of Monetary Economics 13 (January), $31-40$

Falk, Barry and Peter F. Orazem (1985) "The Money Supply Announcements Puzzle: Comment," American Economic Review 75 (June), 562-64

Grossman, Jacob (1981) "The Rationality of Money Supply Expectations and the Short-Run Response of Interest Rates to Monetary Surprises, " Journal of Money, Credit and Banking 13 (November), 409-24

Hardouvelis, Gikas (1984) "Market Pereceptions of Monetary Policy and the Weekly Monetary Announcements, " Journal of Monetary Economics 14 (September), 225-40

Johnston, J. (1972) Econometric Methods, 2nd Edition, McGraw-Hill, New York

Judd, John J. (1984) "Money Supply Announcements, Forward Interest Rates and Budget Deficits," Federal Reserve Bank of San Francisco Economic Review $4(\mathrm{Fall}), 36-46$

Loeys, Jan G. (1985) "Changing Interest Rate Responses to Money Supply Announcements: 1977 - 1983," Journal of Monetary Economics 15 (May), $323-32$

Mankiw, N. Gregory, David E. Runkle and Matthew D. Shapiro (1984) "Are Preliminary Announcements of the Money Stock Rational Forecasts?," Journal of Monetary Economics 14 (July), 15-28

Murphy, Kevin M. and Robert H. Topel (1985) "Estimation and Inference in Two-Step Econometric Models," Journal of Business and Economic Statistics, forthcoming

Pagan, Adrian (1984) "Econometric Issues in the Analysis of Regressions with Generated Regressors, " International Economic Review 25 (February), $221-247$

Quandt, Richard E. (1960) "Tests of the Hypothesis that a Linear Regression System Obeys Two Separate Regimes," Journal of the American Statistical Association 55, 324-30 
Roley, V. Vance (1982) "Weekly Money Supply Announcements and the Volatility of Short-Term Interest Rates, " Federal Reserve Bank of Kansas City Economic Review (Apri1), 3-15

Roley, V. Vance (1983) "The Reponse of Short-Term Interest-Rates to Weekly Money Announcements," Journal of Money, Credit and Banking 15 (August), $344-54$

Roley, V. Vance and Rick Troll (1983) "The Impact of New Economic Information on the Volatility of Short-Term Interest Rates, " Federal Reserve Bank of Kansas City Economic Review 68 (February), 3-15

Roley, V. Vance and Carl E. Walsh (1983) "Monetary Policy Regimes, Expected Inflation, and the Response of Interest Rates to Money Announcements, " National Bureau of Economic Research Working Paper No. 1181, August

Roley, V. Vance and Carl E. Walsh (1984) "Unanticipated Money and Interest Rates," American Economic Review (Papers and Procedings) 74 (May), $49-54$

Shiller, Robert J., John Y. Campbell and Kermit Schoenholtz (1983) "Forward Rates and Future Policy: Interpreting the Term Structure of Interest Rates," Brookings Papers on Economic Activity 1:1983, 173-217

Urich, Thomas J. and Paul Wachtel (1981) "Market Responses to the Weekly Money Supply Announcements in the 1970's," Journal of Finance 36 (December), 1063-72 
TABLE 1

INTEREST RATE EFFECTS OF MONEY SUPPLY ANNOUNCEMENTS USING SURVEY DATA

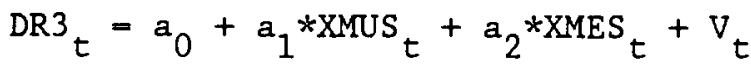

\begin{tabular}{|c|c|c|c|c|c|c|c|c|c|}
\hline $\begin{array}{c}\text { TIME } \\
\text { PERIOD }\end{array}$ & NOB & $\hat{a}_{0}$ & $\hat{a}_{1}$ & $\hat{a}_{2}$ & SER & $\overline{\mathrm{R}}^{2}$ & $\mathrm{DW}$ & $\begin{array}{r}\text { G-Q } \\
\text { TEST }\end{array}$ & $\begin{array}{l}\text { CHOW } \\
\text { TEST }\end{array}$ \\
\hline $\begin{array}{l}\text { Pre- } \\
\text { OCT.'79 } \\
(\text { A. I) }\end{array}$ & 106 & $\begin{array}{c}3.83^{*} \\
(1.12)\end{array}$ & $\begin{array}{l}1.77^{*} \\
(0.62)\end{array}$ & $\begin{array}{l}-1.19 \\
(0.76)\end{array}$ & $\begin{array}{c}9.55 \\
.\end{array}$ & .07 & 1.69 & $\begin{array}{l}4.26^{*} \\
(.00)\end{array}$ & $\begin{array}{l}3.72^{*} \\
(.03)\end{array}$ \\
\hline $\begin{array}{l}\text { OCT.'79/ } \\
\text { OCT. } 82 \\
\text { (B.1) }\end{array}$ & 156 & $\begin{array}{c}4.98 \\
(2.74)\end{array}$ & $\begin{array}{l}8.71^{*} \\
(1.27)\end{array}$ & $\begin{array}{l}-5.62^{*} \\
(1.89)\end{array}$ & 33.70 & .25 & 1.99 & $\begin{array}{l}1.21 \\
(.25)\end{array}$ & $\begin{array}{l}0.53 \\
(.59)\end{array}$ \\
\hline $\begin{array}{l}\text { Post- } \\
\text { OCT. } 82 \\
\text { (C.1) }\end{array}$ & 75 & $\begin{array}{c}1.48 \\
(1.08)\end{array}$ & $\begin{array}{c}3.10^{*} \\
(0.55)\end{array}$ & $\begin{array}{l}-1.19 \\
(0.68)\end{array}$ & 8.62 & .30 & 2.13 & $\begin{array}{l}1.36 \\
(.24)\end{array}$ & $\begin{array}{l}0.45 \\
(.64)\end{array}$ \\
\hline $\begin{array}{l}\text { Pre- } \\
\text { OCT. } 79 \\
(\text { A.2) }\end{array}$ & 104 & $\begin{array}{c}2.73^{*} \\
(0.96)\end{array}$ & $\begin{array}{c}0.80 \\
(0.54)\end{array}$ & $\begin{array}{l}-0.42 \\
(0.66)\end{array}$ & 8.06 & .00 & 1.70 & $\begin{array}{l}2.84^{*} \\
(.00)\end{array}$ & $\begin{array}{l}1.77 \\
(.18)\end{array}$ \\
\hline $\begin{array}{l}\text { Pre- } \\
\text { OCT. } 79 \\
\text { (A.3) }\end{array}$ & 78 & $\begin{array}{c}3.87^{*} \\
(1.24)\end{array}$ & $\begin{array}{c}1.06 \\
(0.66)\end{array}$ & $\begin{array}{l}-0.26 \\
(0.88)\end{array}$ & 8.80 & .01 & 1.76 & $\begin{array}{l}1.50 \\
(.16)\end{array}$ & $\begin{array}{l}1.44 \\
(.24)\end{array}$ \\
\hline
\end{tabular}
Ho: $\angle A .3=B .1=C .1>=8.44^{*}$ $\left(1.8 \times 10^{-6}\right)$
HO: $\angle$ A. $3=$ B. $1>=16.72^{*}$ $\left(1.6 \times 10^{-7}\right)$
HO: $\begin{aligned}<\text { B. }=\text { C. } 1>= & 10.19^{*} \\ & \left(5.8 \times 10^{-5}\right)\end{aligned}$
HO: $\langle$ A. $3=$ C. $1>=2.94$ $\left(5.6 \times 10^{-2}\right)$

Notes - 1. ${ }^{D R} 3_{t}$ is the change in the annualized interest rate on a threemonth U.S. Treasury bill from the close of the market on the day of a money supply announcement in week $t$ to the close on the next trading day. $X{ }_{t} S_{t}$ is the expected change in the money supply announced in week $t$, measured as 
TABLE 1

(continued)

the median of the Money Market Services survey. XMUS $t$ is the unexpected change in the money supply announced in week $t$, measured as the preliminary money supply announcement minus the contemporaneously-released announcement of the revised money supply for the previous week minus XMES $t$. An explanation of the observations used in the sample periods A.1, A.2, A.3, $B .1$, and $C .1$ appears in the appendix.

2. All equations are estimated by ordinaxy least squares. Numbers in parentheses below the estimated coefficients are standard errors. A '*' denotes that the estimated coefficient is significantiy different from zero at the $5 \%$ level of significance. NOB denotes the number of observations in the data set, SER the standard error of the regression, $\overline{\mathrm{R}}^{2}$ the coefficient of deternination adjusted for degrees of freedom and DW the Durbin-Watson statistic. The column entitled G-Q TEST contains the Goldfeld-Quandt test statistic for testing that the error term is homoskedastic and, in parentheses, its marginal significance level. The column entitled CHOW TEST contains the standard Chow test statistic for testing that the coefficients $a_{1}$ and $a_{2}$ are the same in the first half of the sample as they are in the second half and, in parentheses, its marginal significance level. A ' $*$ ' in either of the last two columns indicates that the null hypothesis being tested can be rejected using a $5 \%$ significance level.

3. The test statistics at the bottom of the table test for stability across the various samples by testing for equality of the coefficients $a_{1}$ and $a_{2}$. The numbers in parentheses below the test statistics are marginal significance levels. A ' $*$ ' denotes that the null hypothesis of stability can be rejected using a 58 significance level. The test statistics do not impose the restriction that the variances of the regression error terms are equal across samples. 


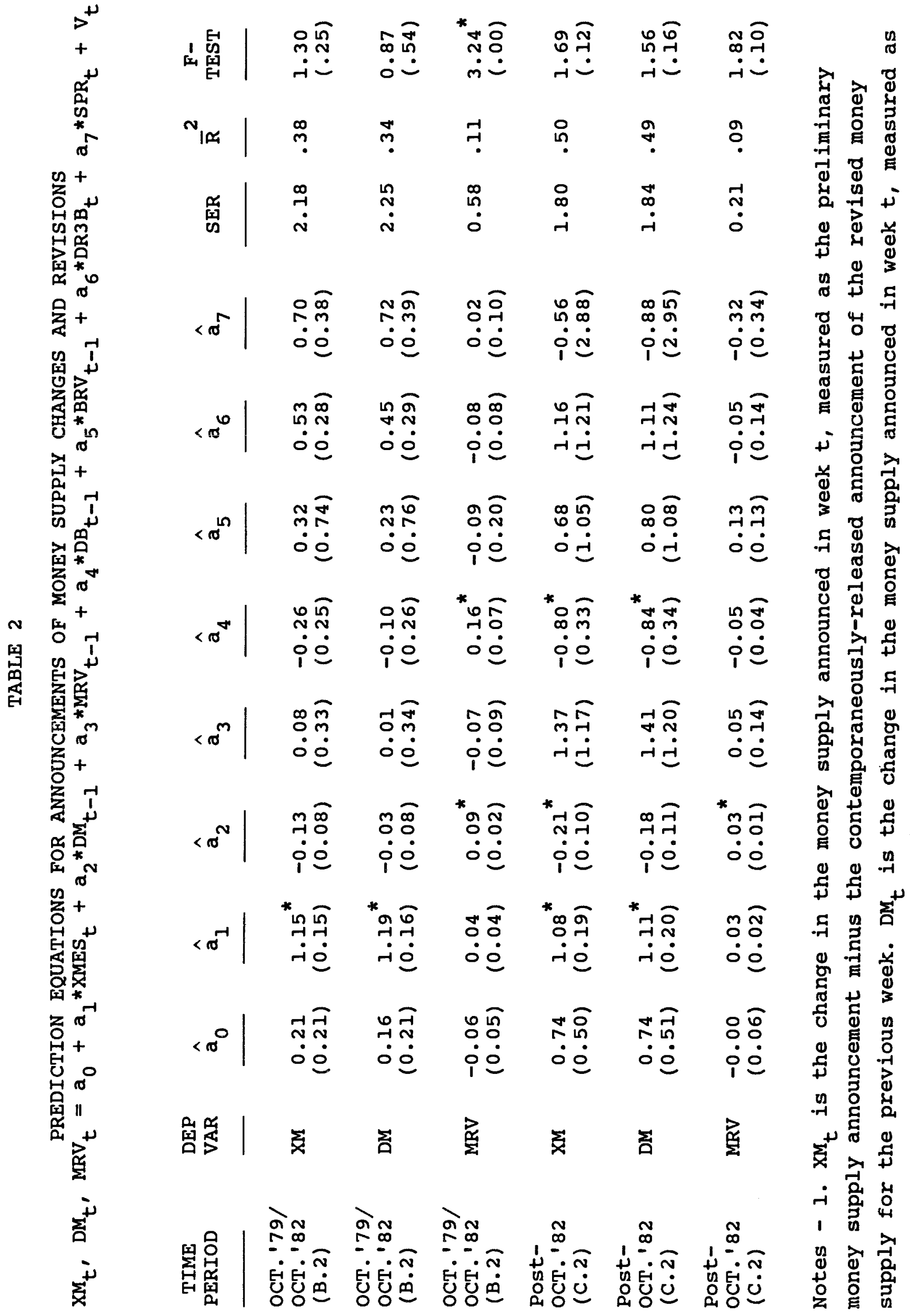




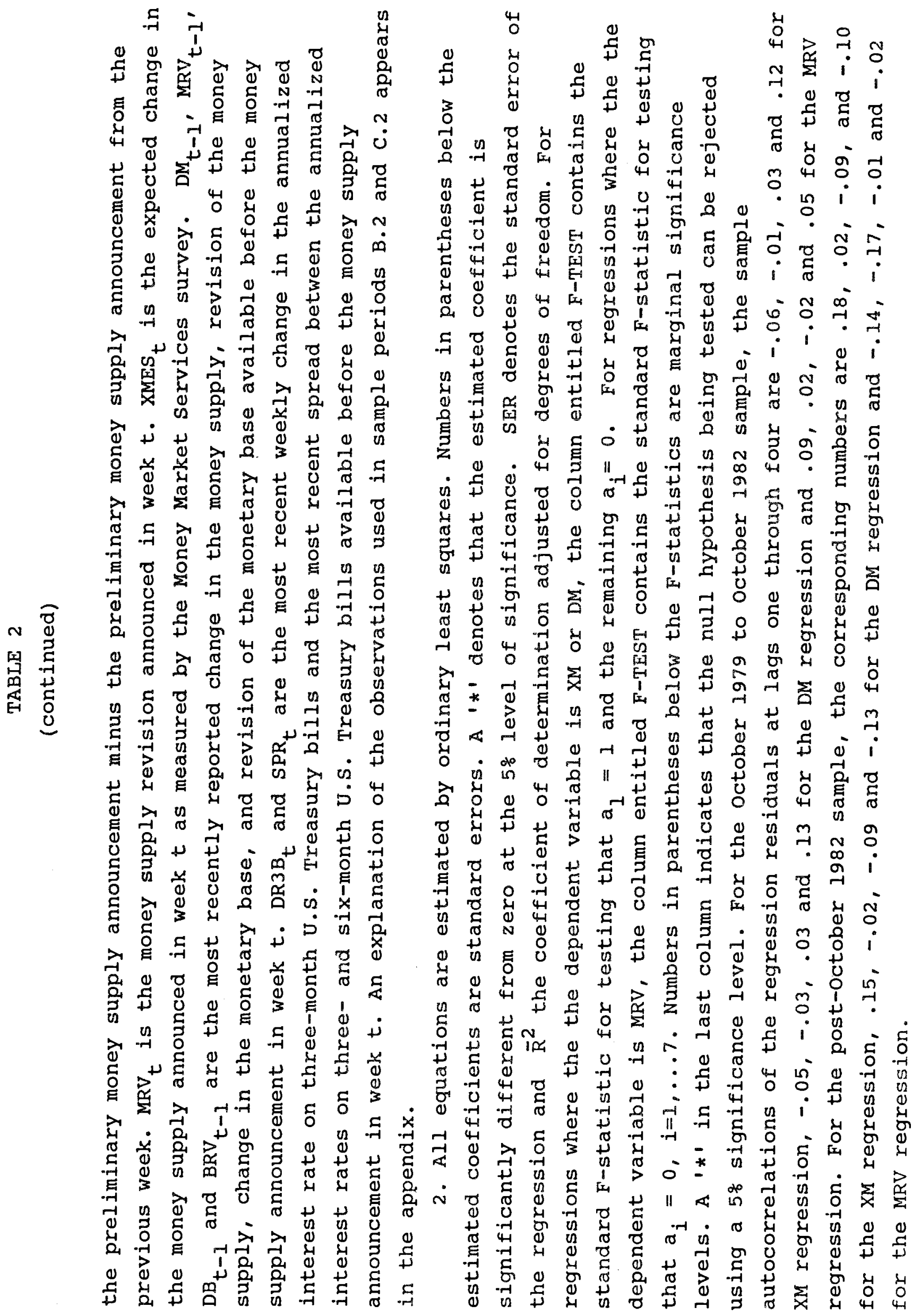




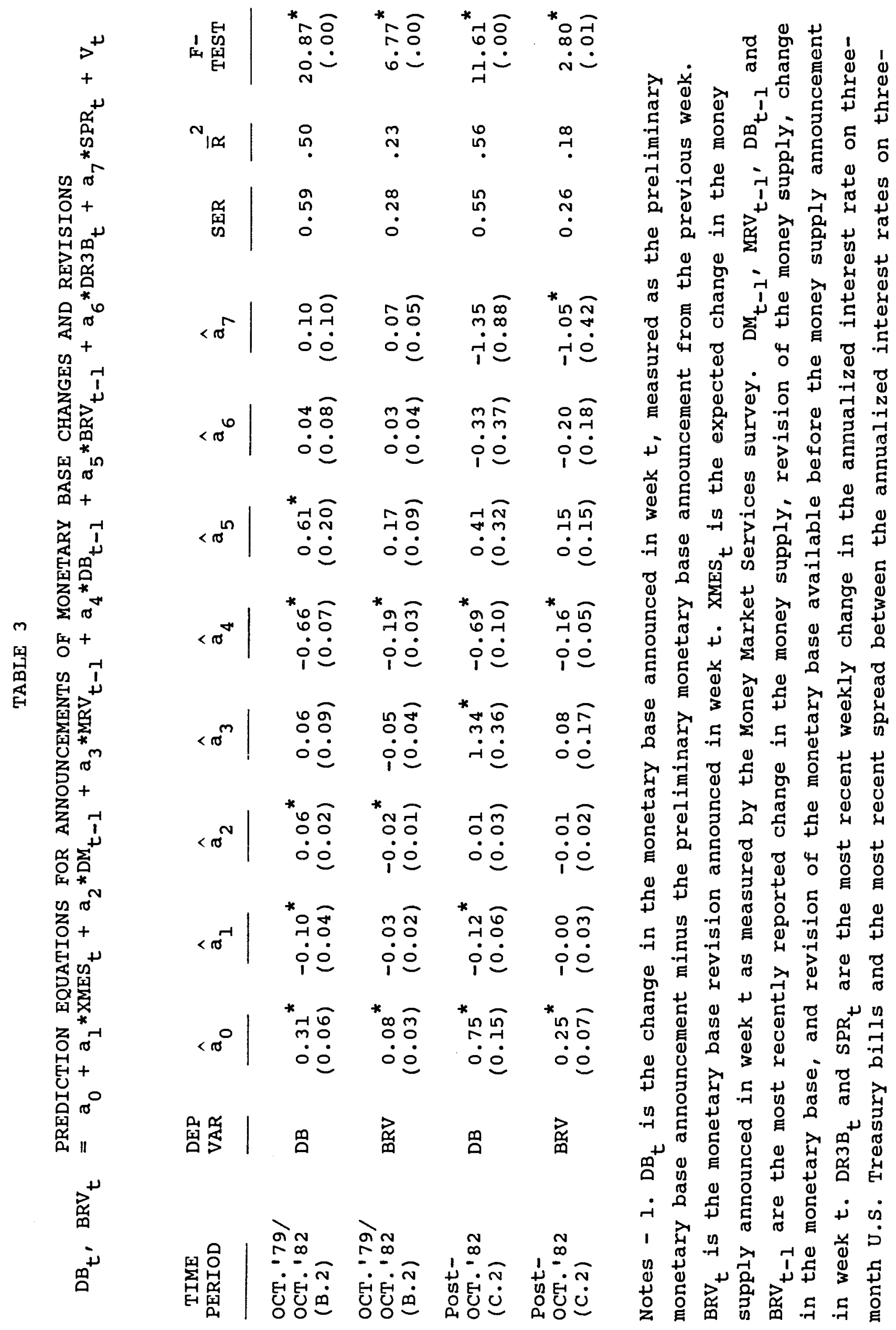




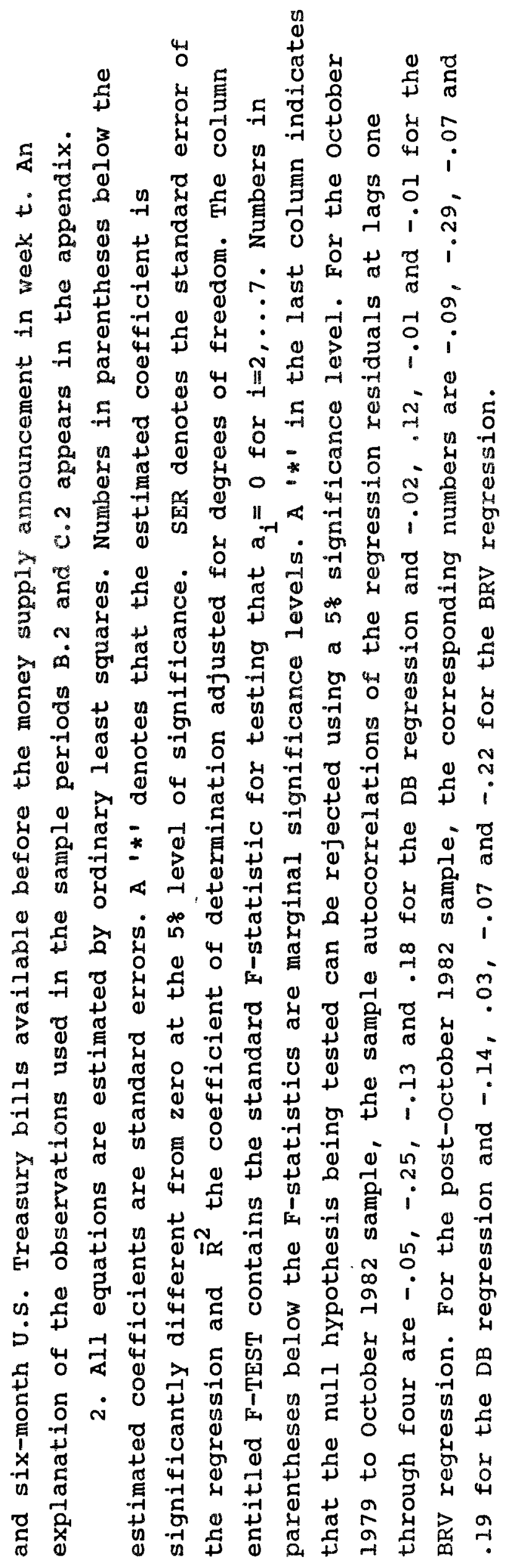




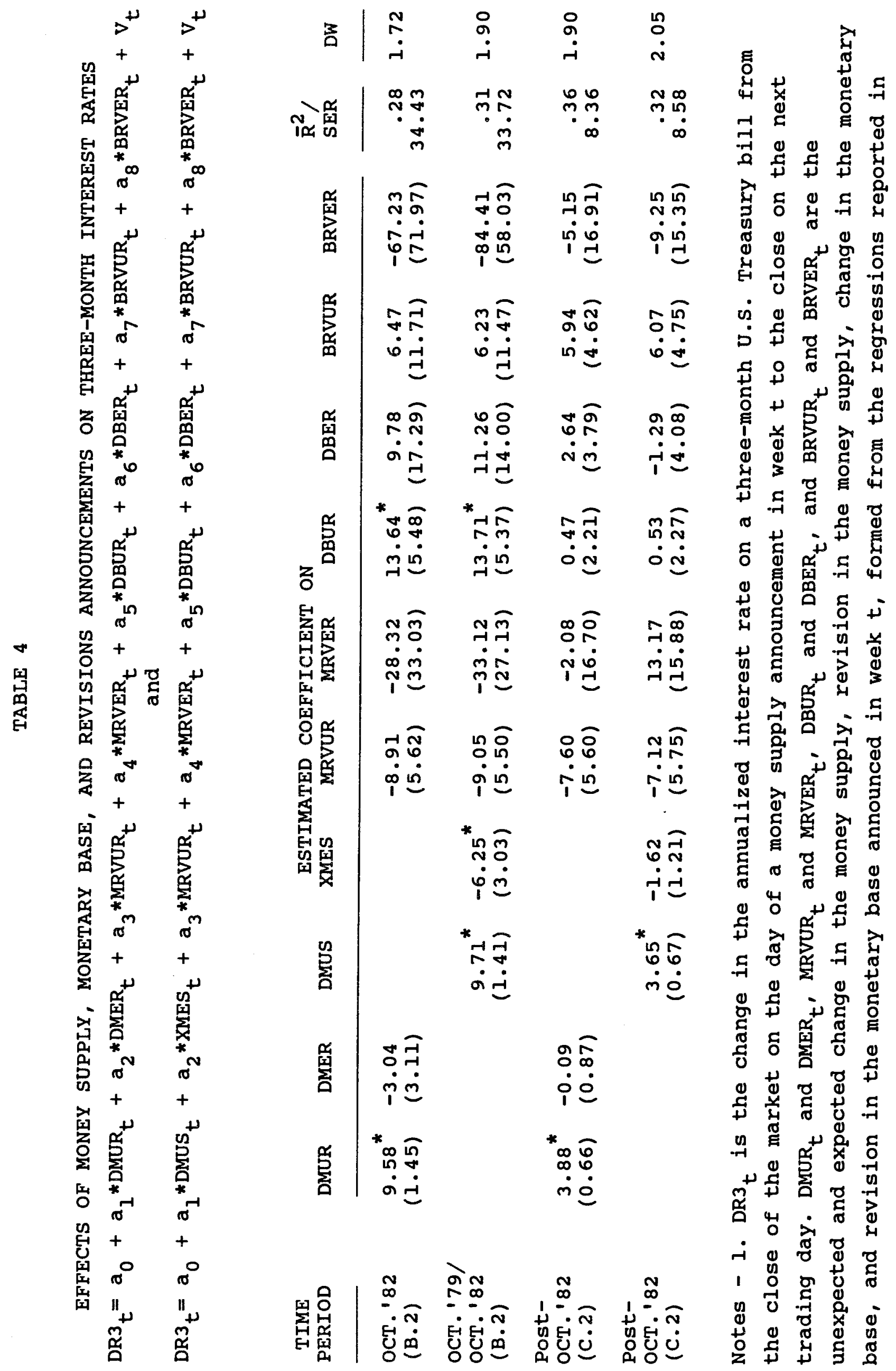




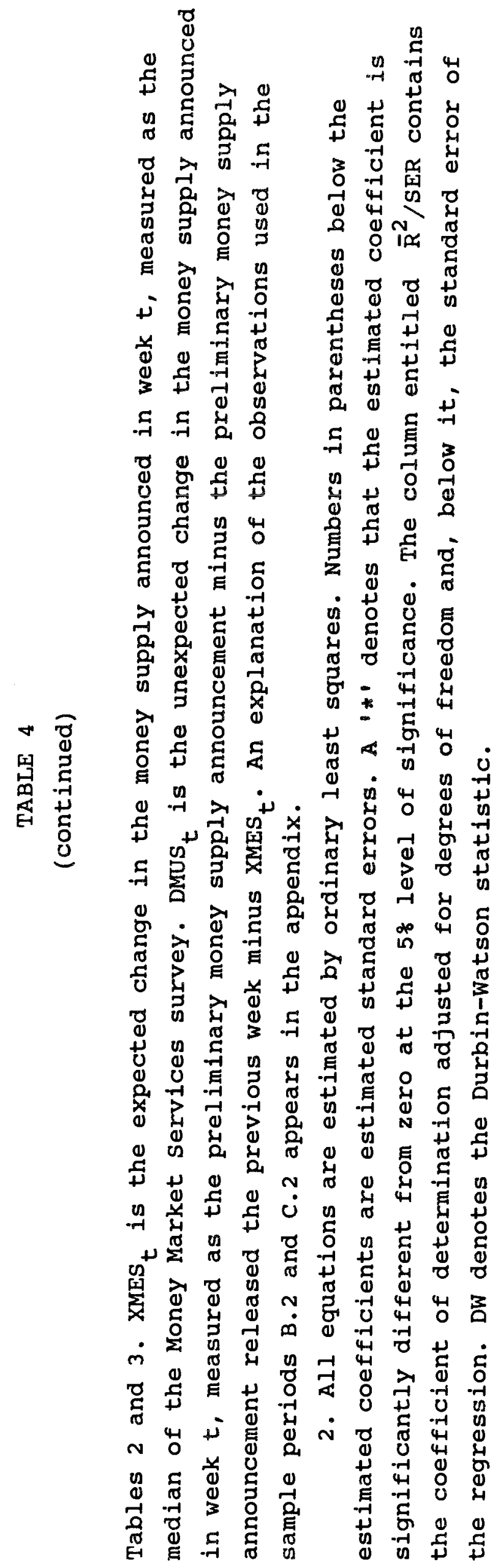


PREDICTIVE ABILITY OF UNEXPECTED ANNOUNCEMENTS FOR FUTURE MONEY SUPPLY CHANGES

$$
\begin{gathered}
\text { MRV }_{t+1}-a_{0}+a_{1} * \text { DMUS }_{t}+a_{2} * \text { DBUR }_{t}+v_{t} \\
\text { and } \\
\text { DMFJ }_{t}-a_{0}+a_{1} * \text { DMUS }_{t}+a_{2} * \text { DBUR }_{t}+v_{t} \quad J=0,4,13
\end{gathered}
$$

\begin{tabular}{|c|c|c|c|c|c|c|c|}
\hline $\begin{array}{c}\text { TIME } \\
\text { PERIOD }\end{array}$ & $\begin{array}{l}\text { DEP } \\
\text { VAR }\end{array}$ & NOB & $\hat{a}_{1}$ & $\hat{a}_{2}$ & SER & $\overline{\mathrm{R}}^{2}$ & DW \\
\hline $\begin{array}{l}\text { OCT.'79/ } \\
\text { OCT. '82 } \\
\text { (B.3) }\end{array}$ & MRV & 114 & $\begin{array}{c}0.07^{*} \\
(0.02)\end{array}$ & $\begin{array}{c}0.08 \\
(0.09)\end{array}$ & 0.55 & .08 & 1.82 \\
\hline $\begin{array}{l}\text { OCT.'79/ } \\
\text { OCT. } 82 \\
\text { (B. } 3 \text { ) }\end{array}$ & DMF0 & 114 & $\begin{array}{l}-0.40^{*} \\
(0.11)\end{array}$ & $\begin{array}{l}-1.12^{*} \\
(0.42)\end{array}$ & 2.67 & .14 & 1.81 \\
\hline $\begin{array}{l}\text { OCT.' } 79 \\
\text { OCT.' } 82 \\
\text { (B. } 3 \text { ) }\end{array}$ & DMF4 & 114 & $\begin{array}{l}-0.17 \\
(0.17) \\
{[1.50]}\end{array}$ & $\begin{array}{l}-1.41^{*} \\
(0.66) \\
{[0.48]}\end{array}$ & 4.22 & .03 & 0.54 \\
\hline $\begin{array}{l}\text { OCT. } 79 / \\
\text { OCT. } 82 \\
\text { (B.3) }\end{array}$ & DMF 13 & 114 & $\begin{array}{l}-0.34 \\
(0.25) \\
{[0.26]}\end{array}$ & $\begin{array}{l}-2.08^{*} \\
(0.97) \\
{[1.04]}\end{array}$ & 6.21 & .03 & 0.34 \\
\hline $\begin{array}{l}\text { Post- } \\
\text { OCT.' } 82 \\
\text { (C. } 3 \text { ) }\end{array}$ & MRV & 51 & $\begin{array}{c}0.02 \\
(0.02)\end{array}$ & $\begin{array}{l}-0.07 \\
(0.07)\end{array}$ & 0.23 & .01 & 1.80 \\
\hline $\begin{array}{l}\text { Post- } \\
\text { OCT.' } 82 \\
(\mathrm{C} .3)\end{array}$ & DMF0 & 51 & $\begin{array}{l}-0.32 \\
(0.19)\end{array}$ & $\begin{array}{l}-0.73 \\
(0.82)\end{array}$ & 2.71 & .04 & 1.71 \\
\hline $\begin{array}{l}\text { Post- } \\
\text { OCT. } 82 \\
(\mathrm{C} .3)\end{array}$ & DMF4 & 51 & $\begin{array}{l}-0.40 \\
(0.33) \\
{[0.27]}\end{array}$ & $\begin{array}{c}0.48 \\
(1.39) \\
{[0.97]}\end{array}$ & 4.61 & -.01 & 0.58 \\
\hline $\begin{array}{l}\text { Post- } \\
\text { OCT.' } 82 \\
\text { (C. } 3 \text { ) }\end{array}$ & DMF13 & 51 & $\begin{array}{l}-0.35 \\
(0.50) \\
{[0.07]}\end{array}$ & $\begin{array}{c}1.13 \\
(2.11) \\
{[0.93]}\end{array}$ & 7.04 & -.03 & 0.23 \\
\hline
\end{tabular}

Notes - 1. $\mathbb{M R V}_{t+1}$ is the money supply revision announced in week $t+1$. DMFO $t$, $D M F 4_{t}$, and $D M F 13_{t}$ are the sum of $M \mathbb{R V}_{t+1}$ and the change in the money supply (including revision) from week $t-1$ to week $t$, week $t-1$ to week $t+4$, and week $t-1$ to week $t+13$, respectively. DMUS $t_{t}$ is the unexpected change in the money 
TABLE 5

(continued)

supply announced in week $t$, constructed using the preliminary money supply announcement minus the preliminary money supply announcement from the previous week and the Money Market Services survey measure of the expected change in the money supply. DBUR $t$ is the unexpected change in the monetary base announced in week $t$, formed from the regressions reported in Table 3 . An explanation of the observations used in the sample periods B.3 and C. 3 appears in the appendix.

2. A1l equations are estimated by ordinary least squares. Numbers below the estimated coefficients in parentheses are standard errors; those in square brackets in the $D M F 4_{t}$ and $D M F 13_{t}$ regressions are t-statistics for testing that the coefficient is equal to the corresponding coefficient in the ${ }^{D M F O}{ }_{t}$ regression. $A$ ' $*$ ' indicates that the estimated coefficient is significantly different from zero at the 58 significance level. NOB denotes the number of observations in the data set, SER the standard error of the regression, $\bar{R}^{2}$ the coefficient of determination adjusted for degrees of freedom and DW the Durbin-Watson statistic. 
PREDICTIVE ABILITY OF UNEXPECTED ANNOUNCEMENTS FOR FUTURE MONETARY BASE CHANGES

$$
\begin{aligned}
& \mathrm{BRV}_{t+1}=\mathrm{a}_{0}+\mathrm{a}_{1} * \mathrm{DMUS}_{t}+\mathrm{a}_{2} * \mathrm{DBUR}_{t}+\mathrm{v}_{t} \\
& \text { and } \\
& \text { DBFJ }_{t}=a_{0}+a_{1} * \text { DMUS }_{t}+a_{2} * \text { DBUR }_{t}+v_{t} \quad \mathrm{~J}=1,4,13
\end{aligned}
$$

\begin{tabular}{|c|c|c|c|c|c|c|c|}
\hline $\begin{array}{c}\text { TIME } \\
\text { PERIOD }\end{array}$ & $\begin{array}{l}\text { DEP } \\
\text { VAR }\end{array}$ & NOB & $\hat{a}_{1}$ & $\hat{a}_{2}$ & SER & $\bar{R}^{2}$ & DW \\
\hline $\begin{array}{l}\text { OCT.'79/ } \\
\text { OCT.' } 82 \\
(B .4)\end{array}$ & $\mathrm{BRV}$ & 103 & $\begin{array}{l}-0.00 \\
(0.01)\end{array}$ & $\begin{array}{l}-0.20^{*} \\
(0.05)\end{array}$ & 0.27 & .14 & 1.29 \\
\hline $\begin{array}{l}\text { OCT.'79/ } \\
\text { OCT.'82 } \\
(\text { B. } 4)\end{array}$ & DBF1 & 103 & $\begin{array}{c}0.12^{*} \\
(0.03)\end{array}$ & $\begin{array}{l}-0.69^{*} \\
(0.11)\end{array}$ & 0.64 & .38 & 2.01 \\
\hline $\begin{array}{l}\text { OCT. } 179 \\
\text { OCT. ' } 82 \\
(\text { B. } 4 \text { ) }\end{array}$ & DBF4 & 103 & $\begin{array}{c}0.05 \\
(0.04) \\
{[1.83]}\end{array}$ & $\begin{array}{l}-0.68^{*} \\
(0.14) \\
{[0.06]}\end{array}$ & 0.84 & .19 & 0.77 \\
\hline $\begin{array}{l}\text { OCT.'79/ } \\
\text { OCT.' } 82 \\
(B .4)\end{array}$ & DBF13 & 103 & $\begin{array}{c}0.05 \\
(0.06) \\
{[1.07]}\end{array}$ & $\begin{array}{l}-0.80^{*} \\
(0.23) \\
{[0.43]}\end{array}$ & 1.35 & .10 & 0.26 \\
\hline $\begin{array}{l}\text { Post- } \\
\text { OCT. ' } 82 \\
(\text { C. } 4 \text { ) }\end{array}$ & BRV & 33 & $\begin{array}{l}-0.03 \\
(0.02)\end{array}$ & $\begin{array}{l}-0.23^{*} \\
(0.10)\end{array}$ & 0.30 & .13 & 1.94 \\
\hline $\begin{array}{l}\text { Post- } \\
\text { OCT. } 82 \\
(C .4)\end{array}$ & DBF1 & 33 & $\begin{array}{l}-0.07 \\
(0.06)\end{array}$ & $\begin{array}{l}-0.95^{*} \\
(0.26)\end{array}$ & 0.73 & .30 & 1.99 \\
\hline $\begin{array}{l}\text { Post- } \\
\text { OCT.' } 82 \\
(C .4)\end{array}$ & $\mathrm{DBF} 4$ & 33 & $\begin{array}{l}-0.11 \\
(0.06) \\
{[0.53]}\end{array}$ & $\begin{array}{l}-0.53^{*} \\
(0.24) \\
{[1.36]}\end{array}$ & 0.69 & .19 & 1.46 \\
\hline $\begin{array}{l}\text { Post- } \\
\text { OCT. } 82 \\
(\text { C. } 4 \text { ) }\end{array}$ & DBF13 & 33 & $\begin{array}{c}-0.09 \\
(0.07) \\
{[0.30]}\end{array}$ & $\begin{array}{l}-0.44 \\
(0.29) \\
{[1.41]}\end{array}$ & 0.83 & .08 & 0.72 \\
\hline
\end{tabular}

Notes - 1. $\mathrm{BRV}_{t+1}$ is the monetary base revision announced in week $t+1 . \mathrm{DBF} 1_{t}$ ' $\mathrm{DBF}_{t}$, and $\mathrm{DBF13}{ }_{t}$ are the sum of $B R V_{t+1}$ and the change in the monetary base (including revision) from week $t$ to week $t+1$, week $t$ to week $t+4$, and week $t$ to week $t+13$, respectively. DMUS $t$ is the unexpected change in the money 
TABLE 6

(continued)

supply announced in week $t$, constructed using the preliminary money supply announcement minus the preliminary money supply announcement from the previous week and the Money Market Services survey measure of the expected change in the money supply. DBUR $t_{t}$ is the unexpected change in the monetary base announced in week $t$, formed from the regressions reported in Table 3 . An explanation of the observations used in the sample periods B. 4 and C.4 appears in the appendix.

2. All equations are estimated by ordinary least squares. Numbers below the estimated coefficients in parentheses are standard errors; those in square brackets in the $\mathrm{DBF}_{4}{ }_{t}$ and $\mathrm{DBF}{ }_{t}{ }_{\mathrm{f}}$ regressions are t-statistics for testing that the coefficient is equal to the corresponding coefficient in the DBF1 ${ }_{t}$ regression. $A$ ' $*$ ' indicates that the estimated coefficient is significantly different from zero at the $5 \%$ significance level. NOB denotes the number of observations in the data set, SER the standard error of the regression, $\overline{\mathrm{R}}^{2}$ the coefficient of determination adjusted for degrees of freedom and DW the Durbin-Watson statistic. 


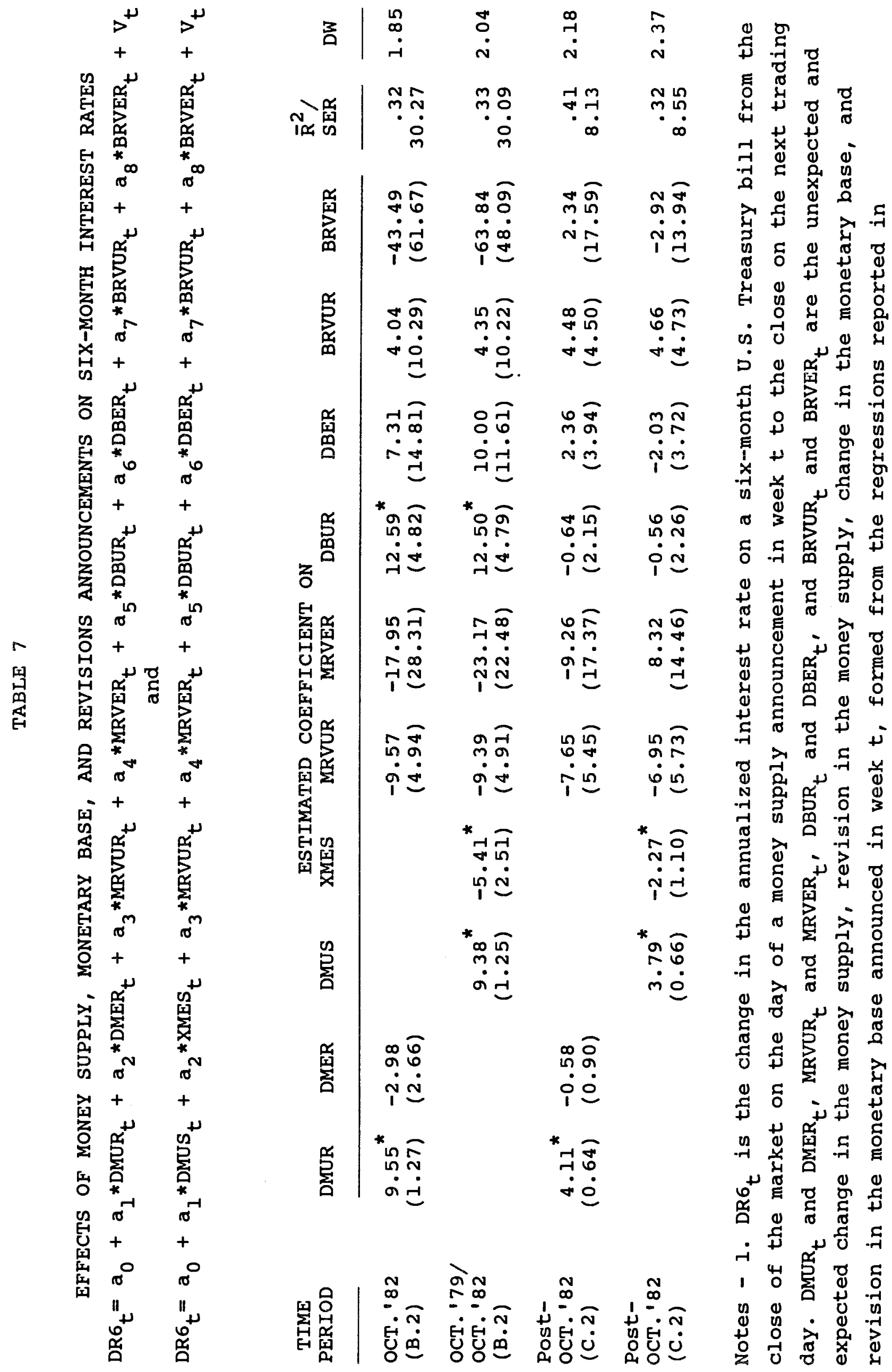




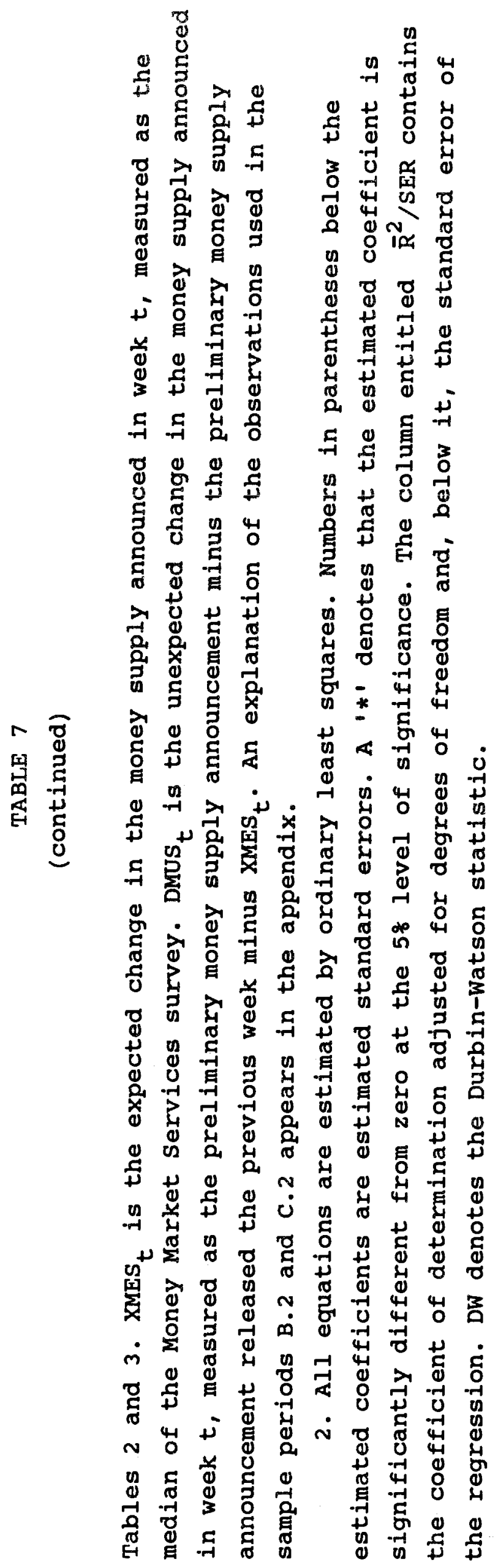




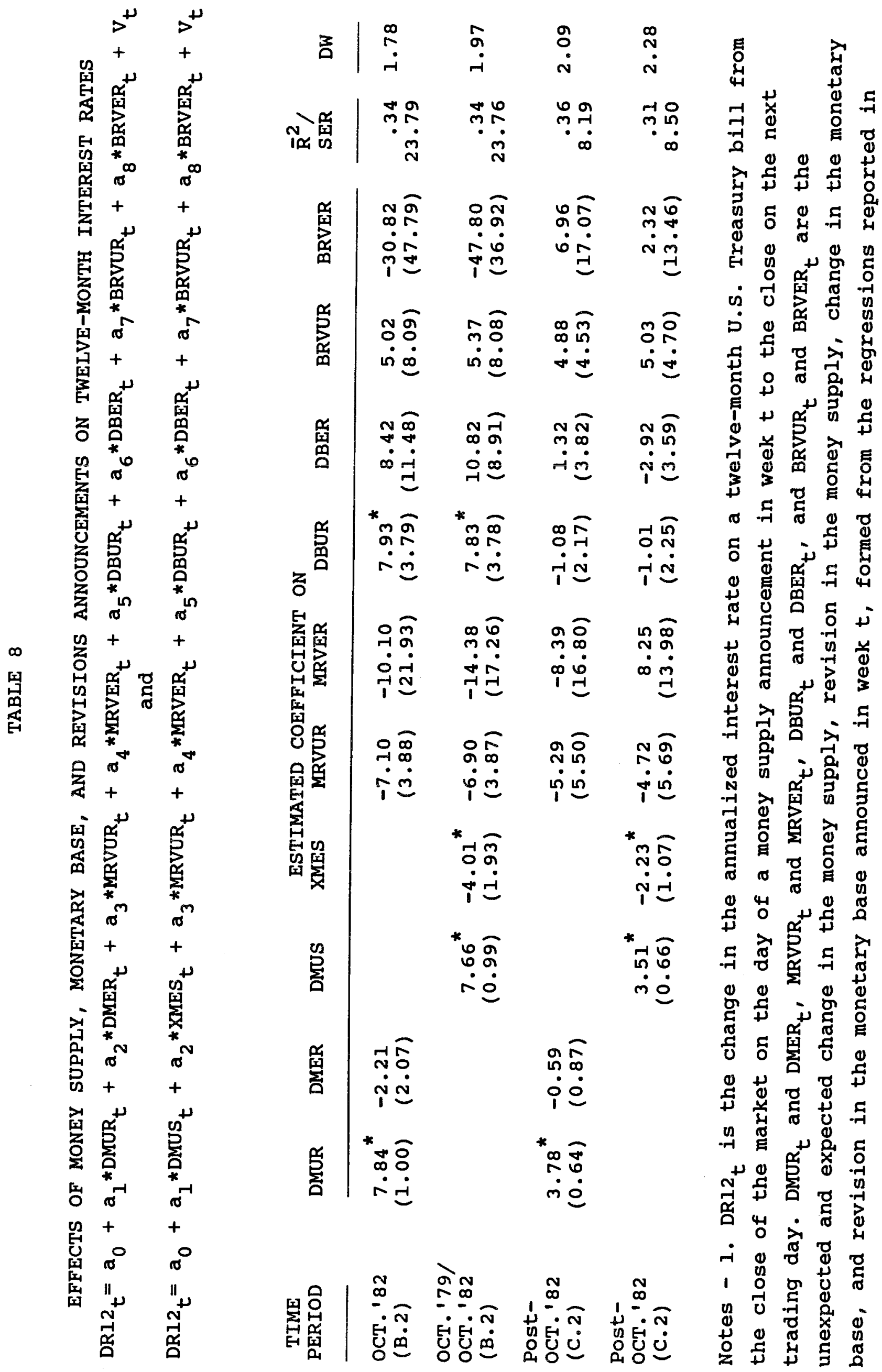




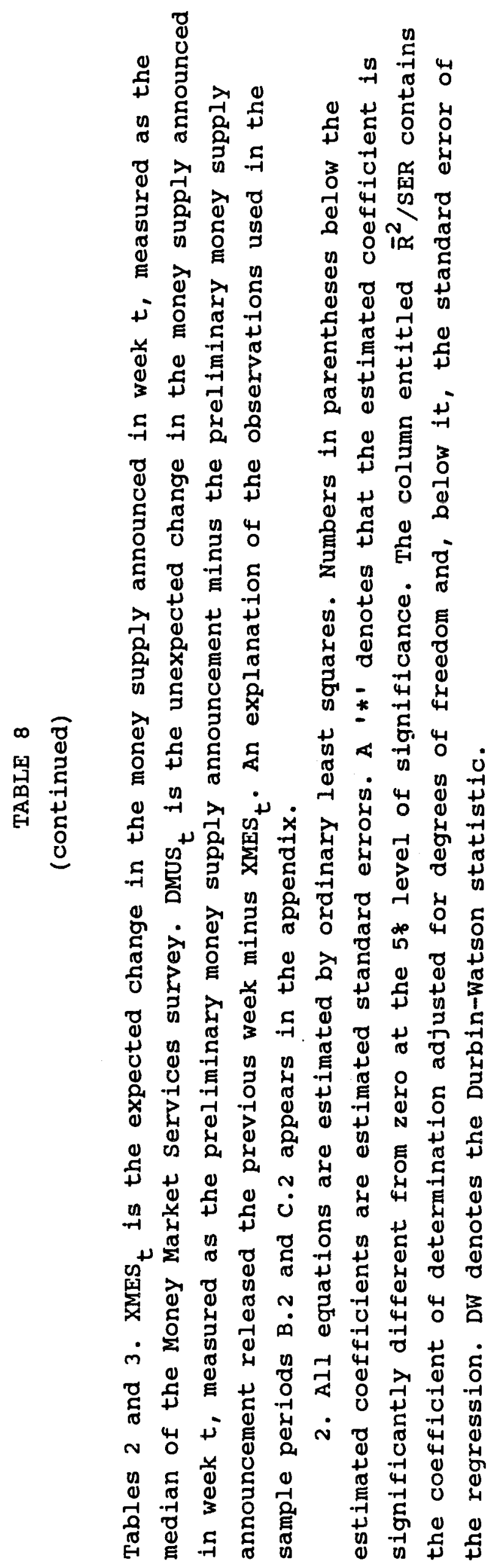


TABLE 9

DIFFERENTIAL IMPACT OF UNEXPECTED ANNOUNCEMENTS ON SHORT- AND LONG-TERM RATES

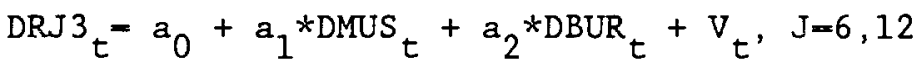

\begin{tabular}{|c|c|c|c|c|c|c|c|}
\hline $\begin{array}{c}\text { TIME } \\
\text { PERIOD }\end{array}$ & $\begin{array}{l}\text { DEP } \\
\text { VAR }\end{array}$ & NOB & $\hat{a}_{1}$ & $\hat{a}_{2}$ & SER & $\overline{\mathrm{R}}^{2}$ & DW \\
\hline $\begin{array}{l}\text { OCT.'79/ } \\
\text { OCT. } 82 \\
\text { (B.2) }\end{array}$ & DR63 & 134 & $\begin{array}{c}4.05^{\star} \\
(0.60)\end{array}$ & $\begin{array}{l}5.02^{*} \\
(2.32)\end{array}$ & 15.27 & .26 & 2.02 \\
\hline $\begin{array}{l}\text { OCT.'79/ } \\
\text { OCT.' } 82 \\
\text { (B. 2) }\end{array}$ & DR123 & 134 & $\begin{array}{c}4.78^{*} \\
(0.68)\end{array}$ & $\begin{array}{c}4.14 \\
(2.62)\end{array}$ & 17.47 & .27 & 1.91 \\
\hline $\begin{array}{l}\text { Post- } \\
\text { OCT.' } 82 \\
\text { (C. } 2 \text { ) }\end{array}$ & DR63 & 60 & $\begin{array}{l}1.67^{*} \\
(0.34)\end{array}$ & $\begin{array}{l}-0.51 \\
(1.26)\end{array}$ & 4.97 & .27 & 2.52 \\
\hline $\begin{array}{l}\text { Post- } \\
\text { OCT.' } 82 \\
\text { (C. } 2 \text { ) }\end{array}$ & DR123 & 60 & $\begin{array}{c}2.27^{\frac{1}{x}} \\
(0.46)\end{array}$ & $\begin{array}{l}-0.56 \\
(1.68)\end{array}$ & 6.64 & .28 & 2.41 \\
\hline
\end{tabular}

Notes - 1. DR6 $3_{t}=\mathrm{DR} 6_{t^{-}} .5 \times \mathrm{DR} 3_{t}$ and $\mathrm{DR} 123_{t}=\mathrm{DR} 12_{t}{ }^{-} .25 * \mathrm{DR} 3_{t}$, where DR3 $t$, DR6 ${ }_{t}$, and $D R 12{ }_{t}$ are the changes in the annualized interest rate on a three-, six-, and twelve-month U.S. Treasury bill from the close of the market on the day of a money supply announcement in week $t$ to the close on the next trading day. DMUS $_{t}$ is the unexpected change in the money supply announced in week $t$, constructed using the preliminary money supply announcement minus the preliminary money supply announcement from the previous week and the Money Market Services survey measure of the expected change in the money supply. DBUR $_{t}$ is the unexpected change in the monetary base announced in week $t$, formed from the regressions reported in Table 3. An explanation of the observations used in the sample periods B. 2 and $C .2$ appears in the appendix.

2. All equations are estimated by ordinary least squares. Numbers in parentheses below the estimated coefficients are standard errors. A ' $*$ ' indicates that the estimated coefficient is significantly different from zero at the 58 significance level. NOB denotes the number of observations in the data set, SER the standard error of the regression, $\bar{R}^{2}$ the coefficient of determination adjusted for degrees of freedom and DW the Durbin-Watson statistic. 
TABLE 10

IMPACT OF UNEXPECTED ANNOUNCEMENTS ON TERM-STRUCTURE PREMIA PREMJ $_{t}=a_{0}+a_{1} *$ DMUS $_{t}+a_{2} *$ DBUR $_{t}+V_{t} \quad J=6,12$

\begin{tabular}{|c|c|c|c|c|c|c|c|}
\hline TIME & DEP & & $\hat{\imath}$ & $\hat{\hat{n}}$ & & $\bar{n}^{2}$ & \\
\hline & & NOB & $a_{1}$ & $a_{2}$ & SER & $\overline{\mathrm{R}}$ & DW \\
\hline $\begin{array}{l}\text { OCT.'79/ } \\
\text { OCT.' } 82 \\
\text { (B.5) }\end{array}$ & PREM6 & 99 & $\begin{array}{l}-7.64 \\
(5.34)\end{array}$ & $\begin{array}{c}12.29 \\
(19.98)\end{array}$ & 124.15 & .00 & .17 \\
\hline $\begin{array}{l}\text { OCT.'79/ } \\
\text { OCT.' } 82 \\
\text { (B.5) }\end{array}$ & PREM12 & 99 & $\begin{array}{l}-4.40 \\
(4.59)\end{array}$ & $\begin{array}{c}10.62 \\
(17.15)\end{array}$ & 106.59 & -.01 & .18 \\
\hline $\begin{array}{l}\text { Post- } \\
\text { OCT. }{ }^{8} 82 \\
\text { (C. } 5 \text { ) }\end{array}$ & PREM6 & 33 & $\begin{array}{c}1.60 \\
(2.15)\end{array}$ & $\begin{array}{l}-3.75 \\
(8.55)\end{array}$ & 24.50 & -.04 & .21 \\
\hline $\begin{array}{l}\text { Post- } \\
\text { OCT.' } 82 \\
\text { (C. } 5 \text { ) }\end{array}$ & PREM12 & 33 & $\begin{array}{c}1.39 \\
(1.26)\end{array}$ & $\begin{array}{l}-4.17 \\
(4.99)\end{array}$ & 14.29 & -.00 & .58 \\
\hline
\end{tabular}

Notes - 1. PREM6 $6_{t}=\mathrm{DR} 6_{t}-.5 * \mathrm{DR} 3_{t}-.5 * \mathrm{R} 3 \mathrm{~A}_{t+13}$ and $\mathrm{PREM} 12_{t}=\mathrm{DR} 12_{t}-.25 * \mathrm{DR} 3_{t}$ - .25*(R3A $\left.A_{t+13}+R 3 A_{t+26}+R 3 A_{t+39}\right)$ where where DR3 ${ }_{t}, D R 6_{t}$, and $D R 12$ are the changes in the annualized interest rate on a three-, six-, and twelve-month U.S. Treasury bill from the close of the market on the day of a money supply announcement in week $t$ to the close on the next trading day and $R 3 A_{t+j}$ is the interest rate on a three-month U.S. Treasury bill after the announcement in week $t+j$. DMUS $t$ is the unexpected change in the money supply announced in week $t$, constructed using the preliminary money supply announcement minus the preliminary money supply announcement from the previous week and the Money Market Services survey measure of the expected change in the money supply. DBUR $t_{t}$ is the unexpected change in the monetary base announced in week $t$, formed from the regressions reported in Table 3 . An explanation of the observations used in the sample periods $B .5$ and $C .5$ appears in the appendix.

2. All equations are estimated by ordinary least squares. Numbers in parentheses below the estimated coefficients are standard errors. A ' *' indicates that the estimated coefficient is significantly different from 
TABLE 10

(continued)

zero at the 58 significance level. NOB denotes the number of observations in the data set, SER the standard error of the regression, $\vec{R}^{2}$ the coefficient of determination adjusted for degrees of freedom and DW the Durbin-Watson statistic. 